\title{
Article
}

\section{GWAS for Stripe Rust Resistance in Wild Emmer Wheat (Triticum dicoccoides) Population: Obstacles and Solutions}

\author{
May Tene ${ }^{1}$, Elina Adhikari ${ }^{2,3}$, Nicolas Cobo ${ }^{4,5}{ }^{(D}$, Katherine W. Jordan ${ }^{2,6}{ }^{(0)}$, Oadi Matny ${ }^{7}(\mathbb{D}$, Isabel Alicia del \\ Blanco ${ }^{4}$, Jonathan Roter ${ }^{1}$, Smadar Ezrati ${ }^{1}$, Liubov Govta ${ }^{8}{ }^{10}$, Jacob Manisterski ${ }^{1}$, Pnina Ben Yehuda ${ }^{1}$, \\ Xianming Chen ${ }^{9,10}$, Brian Steffenson ${ }^{7} \mathbb{D}$, Eduard Akhunov ${ }^{2}$ and Hanan Sela ${ }^{1,8, *(\mathbb{D}}$
}

1 Institute for Cereal Crops Research, Tel Aviv University, Tel Aviv 6139001, Israel; tene.may@gmail.com (M.T.); yoniroter@gmail.com (J.R.); ezrati@tauex.tau.ac.il (S.E.); jacobm@post.tau.ac.il (J.M.); pninaby@tauex.tau.ac.il (P.B.Y.)

2 Department of Plant Pathology, Kansas State University, Manhattan, KS 66502, USA; elina1@ksu.edu (E.A.); katherine.jordan@usda.gov (K.W.J.); eakhunov@ksu.edu (E.A.)

3 Department of Horticulture, University of Wisconsin, Madison, WI 54235, USA

4 Department of Plant Sciences, UC Davis, Davis, CA 95616, USA; nicolas.cobo@ufrontera.cl (N.C.); iadelblanco@ucdavis.edu (I.A.d.B.)

5 Departamento de Producción Agropecuaria, Universidad de La Frontera, Temuco 4811230, Chile

6 USDA-ARS, Hard Winter Wheat Genetics Research Unit, Manhattan, KS 66506, USA

7 Department of Plant Pathology, University of Minnesota, St. Paul, MN 55108, USA; onmatny@umn.edu (O.M.); bsteffen@umn.edu (B.S.)

8 Institute of Evolution, University of Haifa, Haifa 3498838, Israel; liubov@evo.haifa.ac.il

9 US Department of Agriculture Agricultural Research Service, Pullman, WA 99164, USA; xianming@wsu.edu

10 Department of Plant Pathology, Washington State University, Pullman, WA 99164, USA

* Correspondence: hans@evo.haifa.ac.il

check for

updates

Citation: Tene, M.; Adhikari, E.; Cobo, N.; Jordan, K.W.; Matny, O.; del Blanco, I.A.; Roter, J.; Ezrati, S.; Govta, L.; Manisterski, J.; et al. GWAS for Stripe Rust Resistance in Wild Emmer Wheat (Triticum dicoccoides) Population: Obstacles and Solutions. Crops 2022, 2, 42-61. https:// doi.org/10.3390/crops2010005

Academic Editor: Il-Ryong Choi

Received: 30 December 2021

Accepted: 25 February 2022

Published: 2 March 2022

Publisher's Note: MDPI stays neutral with regard to jurisdictional claims in published maps and institutional affiliations.

Copyright: () 2022 by the authors Licensee MDPI, Basel, Switzerland. This article is an open access article distributed under the terms and conditions of the Creative Commons Attribution (CC BY) license (https:// creativecommons.org/licenses/by/ $4.0 /)$.

\begin{abstract}
Stripe rust is a devastating disease in wheat that causes substantial yield loss around the world. The most effective strategy for mitigating yield loss is to develop resistant cultivars. The wild relatives of wheat are good sources of resistance to fungal pathogens. Here, we used a genome-wide association study (GWAS) to identify loci associated with stripe rust (causal agent: Puccinia striiformis f. sp. tritici) resistance in wild emmer (Triticum dicoccoides) at the seedling stage, in the greenhouse, and at the adult plant stage, in the field. We found that the two major loci contributing to resistance in our wild emmer panel were the previously cloned seedling-stage resistance gene, $Y r 15$, and the adult-plant-stage resistance gene, $Y$ r36. Nevertheless, we detected 12 additional minor QTLs that additionally contribute to adult plant resistance and mapped a locus on chromosome 3AS that tentatively harbors a novel seedling resistance gene. The genotype and phenotype data generated for the wild emmer panel, together with the detected SNPs associated with resistance to stripe rust, provide a valuable resource for disease-resistance breeding in durum and bread wheat.
\end{abstract}

Keywords: GWAS; crop wild relatives; stripe rust; wheat; wild emmer; Triticum dicoccoides

\section{Introduction}

Stripe (yellow) rust is a devastating disease in wheat that is caused by the biotrophic fungus Puccinia striiformis $\mathrm{f}$. sp. tritici (Pst). It is ranked fourth among the biotic stress factors in terms of its negative impact on yield, accounting for $2 \%$ of the annual global wheat yield losses [1]. In sub-Saharan Africa, the estimated impact of stripe rust on yield is $5 \%$, while in western Europe, the disease results in a $6 \%$ yield loss [1], with the loss in an individual field being as high as 50\% [2]. Pst is a highly diverse pathogen with new virulent races (pathotypes) appearing every year [3]. Because Pst spores are airborne and travel long distances, the pathogen can rapidly cause large-scale epidemics [2]. Currently, there are 83 designated genes and 67 provisionally designated genes for stripe rust resistance. Moreover, 61 quantitative trait loci (QTLs) have also been described for 
stripe rust resistance in wheat or its wild relatives [4-6]. However, many of the known resistance genes are no longer effective, at least in some parts of the world, due to the emergence of Pst races that are virulent on the resistance genes used for developing widely grown commercial cultivars [3]. There are two main types of resistance to stripe rust: (i) all-stage resistance (ASR), which is usually controlled by one major R gene conferring a strong resistance response that is usually race-specific, and (ii) adult plant resistance (APR), which is effective only at the adult plant stage, is under polygenic control and is less race-specific [5]. Eighteen designated $Y_{r}$ genes confer APR, of which three have been cloned (Yr18, Yr36, and Yr46) [7-9]. Each of the cloned genes belongs to a different protein family. Although APR provides only partial resistance against rusts, it is considered more durable than resistance conferred by ASR, but it is more complicated to use than ASR in breeding programs, due to its polygenic nature.

Wild emmer wheat (Triticum dicoccoides; WEW) is the progenitor of hexaploid bread wheat (T. aestivum) and tetraploid durum wheat (T. durum), which are the most widely grown wheat crops in the world. WEW is indigenous to the Fertile Crescent, where its population is divided into a northern population (Turkey, northern Syria, Iraq, and Iran) and a southern population (Israel, the Palestinian Territories, Jordan, Lebanon, and southern Syria). Previous studies have shown that WEW was domesticated from the northern population, but there are some genetic components from the southern population [10-13]. The southern population is more diverse and is probably the origin of speciation of WEW [13-15]. At the beginning of the 20th century, WEW was proposed as a valuable genetic source for breeding by Aaronsohn (1910) [16], but the progress of transferring traits into domesticated wheat was accelerated only recently with the genome sequencing of WEW, T. durum, and T. aestivum [17-19]. Nevertheless, several stripe rust resistance genes were transferred from WEW into domesticated wheat, including Yr36, $Y r 15, Y r 35, Y r$-SM139, and additional ASR and APR genes that are described in Elkot et al. (2020) $[9,20-23]$.

The genes $Y r 15$ and $Y r 36$ have been cloned. Yr15 encodes a tandem kinase-pseudokinase protein (WTK1) that is located on the short arm of chromosome 1B and confers broadspectrum ASR. Only a few very rare Pst races are virulent on Yr15 [20]. Yr15 is present in $16 \%$ of the WEW accessions from Israel, mainly from the northern part of the country, and is absent in the Fertile Crescent's northern WEW population [24]. The protein structure of the APR gene encoded by Yr36 includes a kinase and a START lipid-binding domain (WKS1). WKS1 was shown to reduce the ability of the thylakoid-associated ascorbate peroxidase to detoxify reactive oxygen species [25]. Yr36 is located on the short arm of chromosome 6B and is present in $67 \%$ of WEW accessions from Israel but is absent from the Fertile Crescent northern WEW population [26].

Genome-wide association studies (GWAS) have been extensively applied to cultivated crops but are far less common in crop wild relatives (CWRs). GWAS in CWRs are very challenging, due to the low levels of $\mathrm{LD}$, complex population structure, and high overall background diversity [27]. To the best of our knowledge, only one GWAS study was conducted in WEW and employed the 9k SNP platform [28]. This study detected ASR-associated loci for stripe rust resistance. In cultivated wheat, many GWAS have been completed, yielding more than 80 QTLs that can be used in marker-assisted selection [5,29-33]. Most of the GWAS for adult plant stripe rust resistance in wheat used single-locus association algorithms that may not capture the multi-locus complexity of agronomic traits. However, in recent years, more GWAS to identify stripe rust APR have been using multi-locus analysis models such as FramCPU, BLINK, MMLM, and mrMLM [33-39].

In the current study, we aimed to elucidate the genetic basis of APR and ASR against stripe rust in WEW from Israel by using a GWAS, which was shown to be a powerful approach for mapping resistance genes in wheat and its wild relatives [40]. The advantage of using WEW for GWAS is the fast rate of linkage disequilibrium (LD) decay in the populations of wheat wild relatives, which increases the resolution of trait mapping [28]. We used complexity-reduced whole-genome sequencing to characterize the genetic diversity 
in the WEW panel. The goals of this study were to explore the utility of WEW from Israel as the source of novel QTLs associated with ASR and APR to Pst.

\section{Materials and Methods}

\subsection{Plant Material}

A diversity panel of 480 WEW accessions was selected from over 2500 accessions housed at the Harold and Adele Lieberman Germplasm Bank, in the Institute for Cereal Crops Research (ICCR) at Tel Aviv University. These accessions were collected from 123 sites across Israel. Selection of the accessions was performed to maximize the geographic distribution of the species and to minimize the number of accessions originating from the same collection site. No more than eight accessions were from the same collection site. Plant passport data and the geographic distribution of accessions in the collection are presented in Table S1 and Figure S1, respectively. For the GWAS of APR, we used a subset of 188 accessions that were susceptible to race PST5006 in the seedling resistance tests (see below).

\subsection{Field Trials}

Field trials to assess APR to Pst were conducted in Israel at two locations, Zafriyya in central Israel and Barkai in northern Israel, during the cropping seasons of 2016, 2017, and 2018. In the USA, field trials were conducted at the University of California's Davis Experimental Field Station, during the cropping seasons of 2016 and 2017. In each of the trials, we planted 1-2 replicates (Table 1). Each replicate consisted of all accessions, in a completely randomized design. In total, the trial was replicated 11 times in eight field-year combinations. Seeds of the test accessions were planted in $0.3 \mathrm{~m}$ rows with $0.5 \mathrm{~m}$ spacing between the rows. Susceptible spreaders, cv. Falchetto in Israel and cv. D6301 in the Davis Experimental Field Station, were planted every 10 rows and around the field to promote stripe rust epidemics. The fields in Israel were artificially inoculated with PST5006 spores mixed with talc. Inoculation was performed every week from mid-January to mid-February. Although natural stripe rust infections occur regularly in California, we inoculated the susceptible spreader with a mixture of Pst spores collected at the Davis field station during the previous season to ensure strong disease pressure. We used the 0-9 infection-type (IT) scale to assess plant reactions to $P s t$, where 0 indicates a highly resistant phenotype (without visible symptoms or signs) and 9 indicates a highly susceptible phenotype, as described by Line and Qayoum (1992) [41]. Photographed scales were used as a reference [42]. Infection types (IT) on the test accessions were scored when the spreader plants were at a disease severity of $70 \%$. Rust scoring was performed twice, approximately 2 weeks apart. Feekes growth-stage estimations were taken at the same time as the stripe rust readings [43].

Table 1. Field experiments: location, year, and the number of replicates.

\begin{tabular}{cccccc}
\hline Field Location & Field Name & $\mathbf{2 0 1 6}$ & $\mathbf{2 0 1 7}$ & $\mathbf{2 0 1 8}$ & $\begin{array}{c}\text { Geographical } \\
\text { Location DD.DD }\end{array}$ \\
\hline Barkai, ISR & BR & 2 rep & 2 rep & 1 rep & $32.47^{\circ} \mathrm{N}, 35.02^{\circ} \mathrm{E}$ \\
\hline Zafriyya, ISR & ZA & 1 rep & 2 rep & 1 rep & $32.00^{\circ} \mathrm{N}, 34.84^{\circ} \mathrm{E}$ \\
\hline Davis, CA, USA & US & 1 rep & 1 rep & & $38.53^{\circ} \mathrm{N}, 121.77^{\circ} \mathrm{W}$ \\
\hline
\end{tabular}

\subsection{Seedling Resistance Tests}

The WEW panel was screened for seedling resistance to four Pst isolates, as described in Huang et al. (2018) [44]. The PST5006 Pst isolate, representing race 38E134 (race PST5006 hereafter), originated from Israel, while the three other isolates, representing races PSTv-14, PSTv-37, and PSTv-40, originated from the United States [45,46]. Rust assays with the Israeli isolate were conducted at Tel Aviv University, whereas assays for isolates from the United States were conducted at the University of Minnesota. The rust inoculum suspension consisting of $700 \mu \mathrm{L}$ Soltrol ${ }^{\circledR}$ oil (Chevron Phillips Chemical) and $10 \mathrm{mg}$ of spores, was 
sprayed onto 12-day-old plants at the two-leaf stage. Post inoculation, plants were placed inside a dew chamber at $10{ }^{\circ} \mathrm{C}$ and $100 \% \mathrm{RH}$ for $24 \mathrm{~h}$. Thereafter, for the incubation period, plants were moved into a growth chamber with a diurnal temperature cycle, gradually changing from $10^{\circ} \mathrm{C}$ at 2 a.m. to $15^{\circ} \mathrm{C}$ at 2 p.m., with a 16 -hour photoperiod provided by high-pressure sodium lamps. Each accession was tested in three replicates. The readings were taken using the 0-9 scale, as described above. The highest IT for each accession to each race was recorded. A unified IT value for all races was calculated as the maximum IT among all races for each accession (UIT hereafter).

\subsection{Genotyping}

DNA was extracted from the leaves of 1-month-old plants using the DNeasy Plant Pro Kit (Qiagen), according to the manufacturer's protocol. The panel was genotyped with the genotyping by sequencing method (GBS), using PstI-MseI restriction enzymes [47,48]. The wild emmer Zavitan genome, version 1 (WEW_v1.0), was used as a reference [17]. Variants were called using the TASSEL GBS pipeline [49]. The genotype data were imputed using BEAGLE with all available variants [50]. For GWAS, we used only those variants and accessions that originally had less than $50 \%$ of missing data. The data were filtered for a minor allele frequency (MAF) of $1 \%$. Variants that had more than $10 \%$ heterozygosity were removed. Filtering was performed using TASSEL v5 [49].

\subsection{Yr36 and Yr15 Presence Markers}

The primers WKS1_557F and WKS1_559R were used to detect the presence of Yr36 [9]. PCR conditions were as described by Huang et al. (2016) [26]. The KASP marker Kin1 was used to detect the presence of the functional ASR gene, Yr15 [24].

\subsection{Statistical Analysis}

The manipulation of data was performed using the data.table $\mathrm{R}$ package [51]. To test the differences between environments, we plotted a biplot using the GGEBiplotGUI $\mathrm{R}$ package [52]. On the basis of the observation that the differences between replicates were similar to the differences between fields (Figure 1), we considered each replicate as an environment. The best linear unbiased predictors for IT (BLUP-IT) were calculated for each accession, using the rrBLUP R package [53]. The BLUP calculation accounted for the fields (environments) and the growth stage (Feekes) as fixed effects. Broad-sense heritability $\left(\mathrm{H}^{2}\right)$ was calculated using the repeatability function within the heritability $R$ package [54].

\subsection{PCA}

Principal component analysis (PCA), used to detect population structure, was based on $10 \%$ of the total variants in the genotype matrix and was performed using the pcaMethods $\mathrm{R}$ package [55]. Additionally, we conducted spatial PCA (sPCA), as implemented in the adegenet R package [56]. The sPCA yields scores that summarize both the genetic variability and the spatial structure among individuals [57]. 


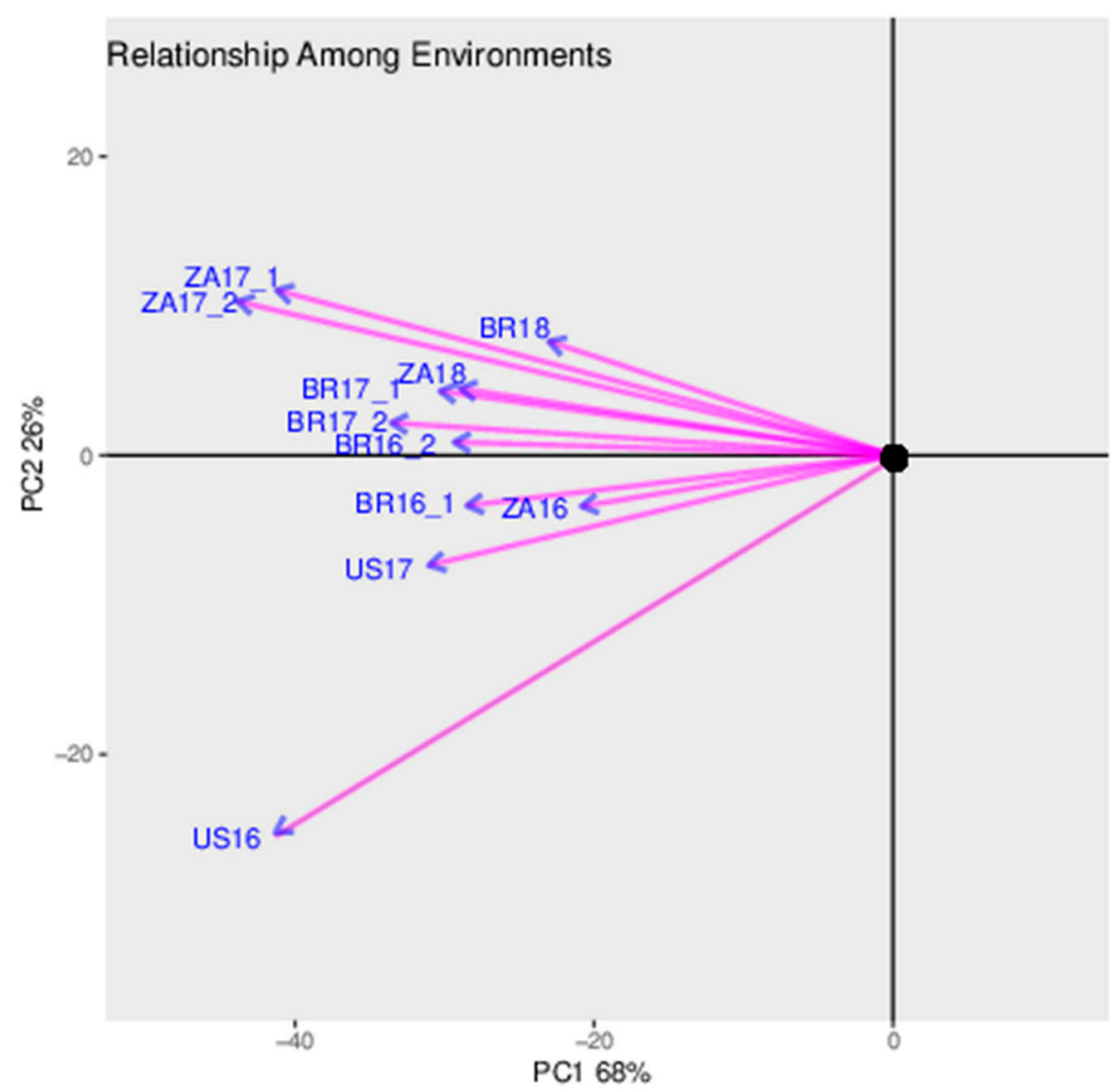

Figure 1. Environment biplot of the 11 environments (fields) used in the study, showing the relationship of IT distribution among environments. This is a genotype plus genotype-by-environment (GGE) biplot. The plot is based on the infection-type (IT) scores in the environments.

\subsection{GWAS of Stripe Rust APR}

The GAPIT [34] and mrMLM [35] R packages were used to detect associations between variants and BLUP-IT. We used all models of the two packages, except for GLM in GAPIT, which showed inflation of low $p$-values, and the pLARmEB method from the mrMLM package, which had a technical problem. GAPIT uses single and multi-variant detection, while mrMLM is multivariate-oriented. To correct for population structure bias, the first three principal components of PCA were used as fixed-effect covariates, and a kinship matrix was used as a random effect. The PCA and the kinship matrix were calculated using the GWAS software. On the basis of the quantile-quantile (QQ) plots, a $-\log _{10} p$-value $=4 \mathrm{w}$ as selected as the threshold for significance (Figure 2). Above this point, $p$-values deviated from the trend line of the expected uniform distribution. The 20 best variants that had a $-\log _{10} p$-value $>4$ in at least two models were tested together in one mixed model, using the lmekin function from the coxme R package [58]. The model included the 20 variants as fixed effects, while the environment, accession ID, and kinship matrix of the accessions were included as random effects. The model was permuted 1000 times. Only 13 variants were significant in the mixed model, including the Yr36 marker $(p<0.05)$. To find the best combination of subsets of the 13 variants, all possible subset combinations were tested using the lmekin fitted model within the MuMIn R function [59]. The AIC (Akaike information criterion) [60] was used as the criterion for the best combination. Interactions between variants were tested using lmekin. 

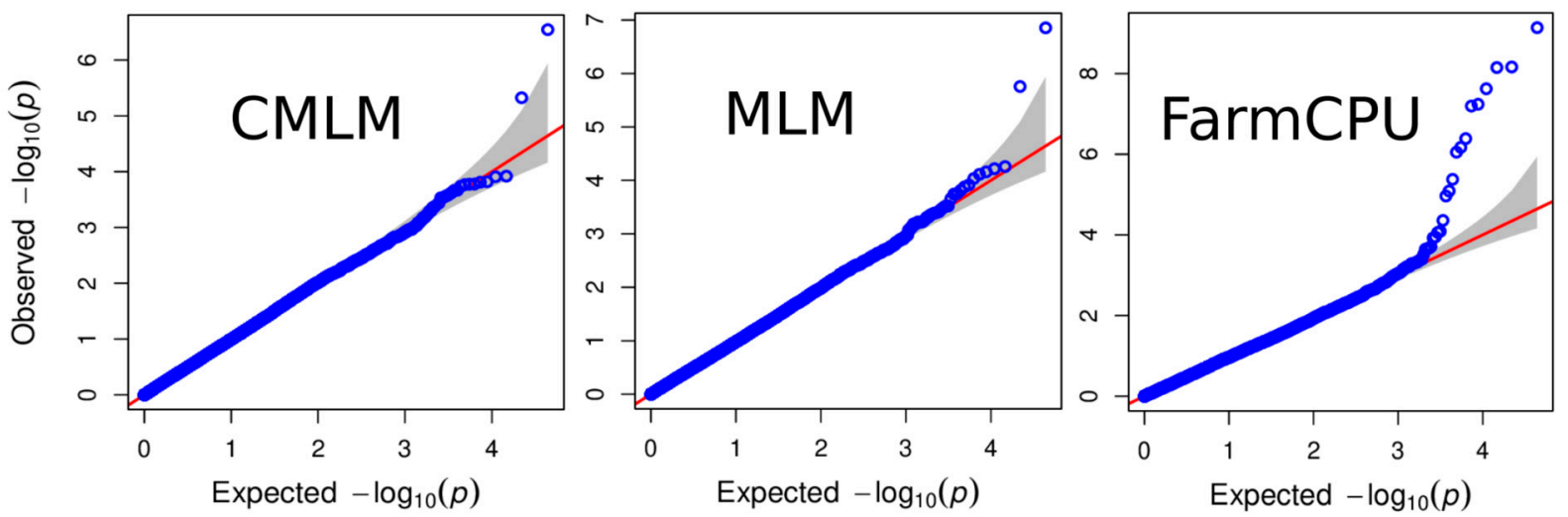

Figure 2. Quantile-quantile (QQ) plots of observed vs. expected $p$-values, obtained from the GWAS models used to detect MTA for adult plant BLUP-IT.

\subsection{GWAS for ASR}

GWAS was implemented for detecting the associations with ITs obtained from the seedling trials. We used all the models in GAPIT except GLM and SUPER, which demonstrated inflation in low $p$-values. We tested the reactions to each $P$ st race separately with each of the six models. The results from all runs of the individual races were collated using the data.table package in $\mathrm{R}$. The association score threshold was set to a false discovery rate (FDR)-adjusted $p$-value ( $\left.p_{\text {adj }}\right)$ of $<0.05$ [61]. Additionally, we tested the association with UIT scores. In the latter test, we also included the SUPER model. We validated the results of the UIT association test using the ITs from each race separately. To perform this, we used a mixed model, as implemented in the lmekin function in the coxme R package, where the dependent variable was the IT for each accession (Pst-race combination); the variants from the two UIT significant loci (Qpst.icci-1BS and Qpst.icci-3AS) were fixed effects, and the accession ID, Pst race, and the kinship matrix were random effects. The model was permuted 10,000 times.

\section{Results}

\subsection{Field Tests}

The distribution of IT values across the 11 environments is presented in Figure 3 and Tables S2 and S3. The majority of the accessions had high ITs (>7), especially at the Israeli sites. ITs on accessions tested at Davis showed a more even distribution. The broad-sense heritability $\left(\mathrm{H}^{2}\right)$ for ITs was very high at 0.91 . The Pearson correlation coefficients between the environments ranged between 0.39 and 0.84 (mean $0.62 \pm 0.15$ ), where the highest correlations ( $>0.8$ ) were between replicates within the same field (Figure 4 ). The range of the BLUP values for ITs was 2.7-8.8, while BLUP values for accessions that were susceptible in the seedling test ranged between 4.0 and 8.8 (Figure 3). Twenty accessions, scored as susceptible (IT $>6)$ at the seedling stage, had a resistant response to stripe rust in the field experiments (BLUP-IT values $<5$ ), suggesting that these accessions may carry levels of APR that would be useful in breeding. 


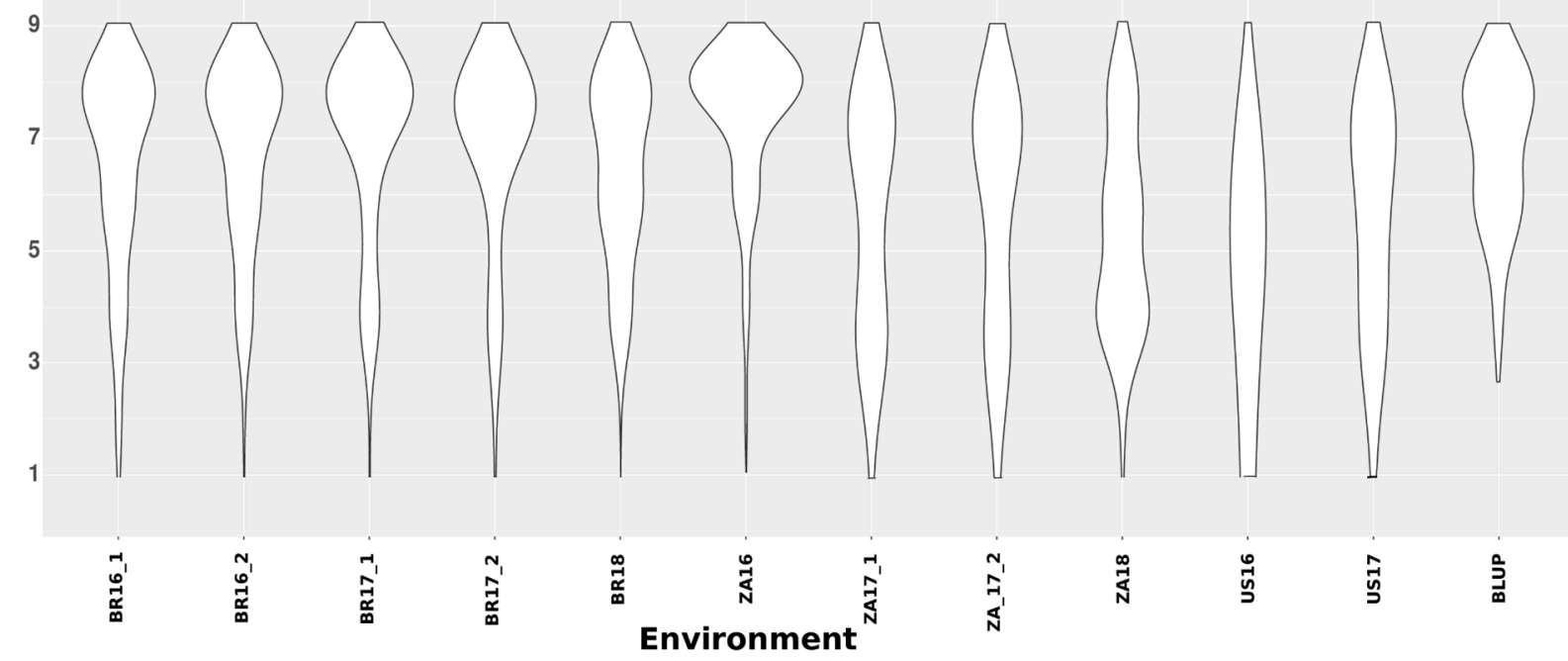

Figure 3. Violin plots showing the distribution of infection types (ITs) for stripe rust in the field trials.

Pearson Correlation

1.00
0.75
0.50
0.25
0.00

ZA17_1

ZA18

BR18

ZA16

BR16_1

BR16_2

BR17_2

BR17_1
US16

$0.71 \quad 0.69$

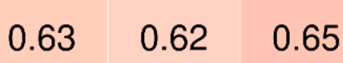

$\begin{array}{llll}0.51 & 0.65 & 0.63 & 0.61\end{array}$

$\begin{array}{lllll}0.47 & 0.53 & 0.53 & 0.52 & 0.48\end{array}$

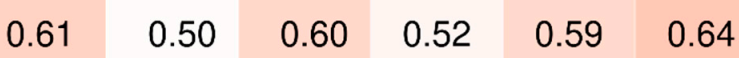

$\begin{array}{lllllll}0.58 & 0.58 & 0.53 & 0.57 & 0.56 & 0.63 & 0.62\end{array}$

$\begin{array}{lllllllll}0.55 & 0.56 & 0.51 & 0.51 & 0.64 & 0.63 & 0.75 & 0.74\end{array}$

0.80

$\begin{array}{llll}0.51 & 0.54 & 0.43 & 0.51\end{array}$

$0.57 \quad 0.54$

$0.69 \quad 0.67$

US17

$$
\begin{array}{l|l}
0.55 & 0.61
\end{array}
$$$$
0.52 \quad 0.51
$$

$0.40 \quad 0.39$

0.59

$\begin{array}{lll}0.45 & 0.63 & 0.60\end{array}$
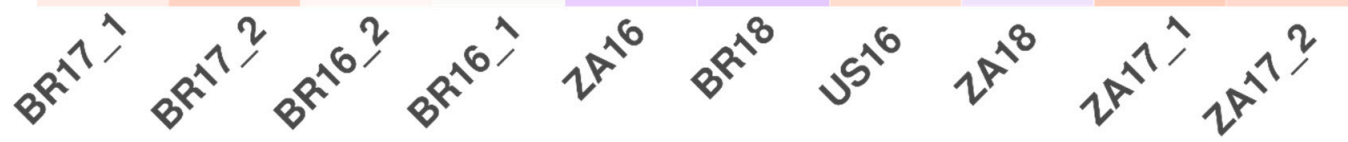

Figure 4. Correlation of IT with PST between field trials (environments). 
The genotype plus genotype-by-environment (GGE) biplot showed that the differences between replicates from the same field were similar to the differences between fields (Figure 1). Therefore, we treated field replicates as different environments.

\subsection{Seedling Resistance Scoring}

Susceptible reactions (IT $>6$ ) were the most common phenotypes observed. For the races PSTv-14, PSTv-37, PSTv-40, and PST5006, resistant reactions were observed in 19\%, $8 \%, 12 \%$, and $17 \%$ of the panel, respectively (Figure 5). The IT distribution was different among the Pst races. To PST5006, most of the accessions were highly susceptible (IT = 9), with only a few accessions exhibiting highly resistant reactions (IT $=1)$. In the case of PSTv-37, most of the accessions showed intermediate reactions, with ITs ranging between 5 and 7 (Figure 5).

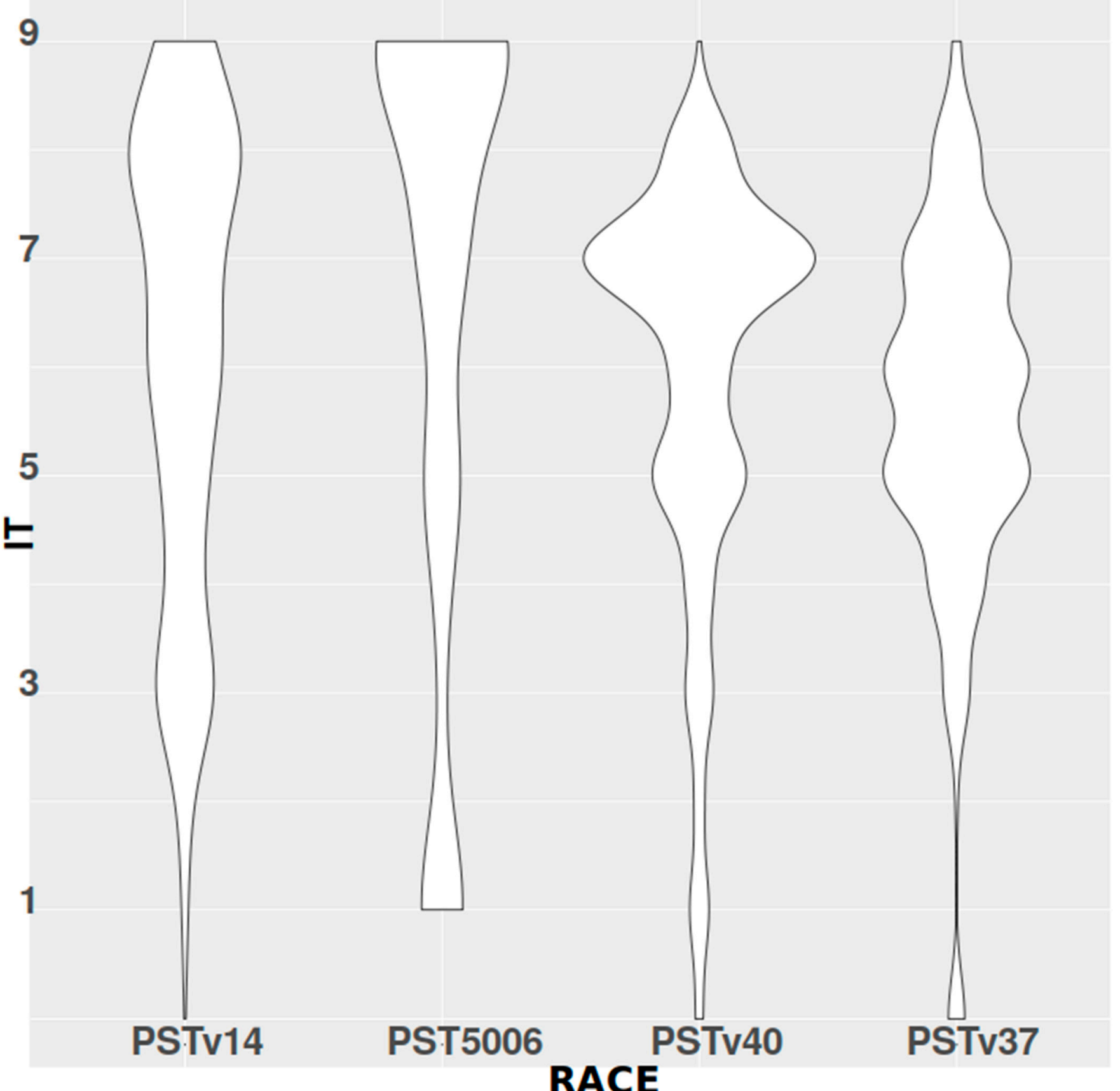

Figure 5. Violin plots showing the distribution of infection types (ITs) to stripe rust in the field trials. 


\subsection{Genotyping}

Complexity-reduced genotyping resulted in the discovery of 341,228 variants. The entire dataset was imputed using BEAGLE with default arguments, then filtered to retain variants with MAF $>1 \%$ and a proportion of missing data in individual accessions, or SNP sites $<50 \%$ in the raw data. Using the genotypic data, we conducted PCA and identified a separate group of $\sim 70$ accessions belonging to the subgroup of T. dicoccoides ssp. judaicum. These accessions were removed from the analysis since our previous study showed that they have a substantial effect on LD that may increase the false-positive rate [28]. The final panel for the seedling resistance GWAS was composed of 419 accessions and 202,113 variants, whereas for the APR GWAS, the panel was composed of 188 accessions and 44,052 variants. Only those accessions susceptible to PST5006 were included in the APR GWAS, to avoid the masking of APR by major-effect seedling resistance genes.

\subsection{Population Structure}

sPCA was conducted only for the T. dicoccoides ssp. horanum accessions (those that were not detected as the judaicum spp.). The sPCA resulted in one PC that describes most of the spatial genetic variance. The sPCA revealed a clear geographic structure along a north-south axis, where accessions in the south were associated with positive values of PC1, while accessions from the north were associated with negative values. The accessions from the north were much more diverse than the accessions from the south (Figure S1). Superimposing APR BLUP-IT values on a PCA plot revealed that most of the resistant accessions were clustered in one corner of the plot, with negative PC1 values. This cluster originated mainly from northern Israel (Figure S2).

Linkage disequilibrium analysis revealed a rapid decay in $\mathrm{LD}$ along the chromosomes. Average LD values were halved from $r^{2}=0.85$ to $r^{2}=0.425$ within $800 \mathrm{bp}$ and dropped below $r^{2}=0.2$ within $6 \mathrm{kbp}$ and below $r^{2}=0.1$ within $150 \mathrm{kbp}$ (Figure S3).

\subsection{GWAS for ASR}

GWAS for seedling resistance was performed using six models in the GAPIT R package for the ITs to four individual races of Pst (PSTv-14, PSTv-37, PSTv-40, and PST5006) and for UIT. The significance threshold was set to a FDR-adjusted $p$-value $\left(p_{\text {adj }}\right)=0.05$. Two loci were associated with the UIT for all methods. One $30 \mathrm{Mb}$ QTL (Qpst.icci-1BS hereafter) spanning several variants was identified in the distal region of the chromosome arm 1BS (63-93 Mb). The region encompassed by this QTL contains the Yr15 locus, located close to the QTL distal border at $\sim 65 \mathrm{Mb}$ (1B:64865841) [20]. The variant with the strongest GWAS signal in Qpst.icci-1BS was located at $\sim 92 \mathrm{Mb}$ (1B:91719364), which is close to the proximal border of the QTL region (FarmCPU model MAF $=12 \%$; $p_{\text {adj }}=2.69 \times 10^{-9}$ ). Variants in the region within Qpst.icci-1BS (63-93 Mb) were associated with the presence of the functional $Y r 15$ gene, as determined by the $Y r 15$ Kin1 KASP marker, especially variant 1B:65387461 (Fisher test $p=5.5 \times 10^{-5}, N=50$ ). A second locus associated with IT was found on the chromosome arm 3AS at $25 \mathrm{Mb}$ (3A:25212609) (FarmCPU model, $\mathrm{MAF}=4.5 \% ; p_{\text {adj }}=5.38 \times 10^{-10} ;$ Figure S4; Qpst.icci-3AS hereafter). The seedling IT effect of the two marker-trait associations (MTAs) differed significantly from race to race. The highest effects were observed for race PST5006 (5.4-5.2), while for race PSTv-37, the effects were much lower (1.6-1.8; Figure S5). The distributions of effects for each of the two QTLs were similar (1.5-5.5). We tested the two QTLs together in a mixed model using the lmekin $\mathrm{R}$ function, where the dependent variable was the IT for each accession. Variants from Qpst.icci-1BS and Qpst.icci-3AS were set as fixed effects. The accession ID, Pst race, and kinship matrix were set as random effects. The model was permuted 10,000 times. Qpst.icci-1BS and Qpst.icci-3AS were significantly associated with IT in the original model ( $p=0$ and $p=17 \times 10^{-5}$, respectively) and after the permutation test analysis $(p<0.0001$ and $p=0.002$, respectively). Three accessions with no favorable alleles in Qpst.icci-1BS and Qpst.icci-3AS were resistant $(\mathrm{IT}<5)$ to all the $P$ st races tested. Because they do not carry the Yr15 favorable allele and still show a broad resistance to Pst, these accessions from Central 
Samaria, Lower Galilee, and Golan Heights can be used for discovering new Pst resistance loci other than Yr15.

From the GWAS results conducted for each race separately, we removed the results of PSTv-40 tested with the single-variant models, namely, MLM, CMLM, and ECMLM, as well as all results from the SUPER model since the QQ plots showed inflated low $p$-values for these analyses (Figure S6). The remaining results did not converge to a single significant variant across all races and all models. However, all race $\times$ model combinations showed association signals in the Qpst.icci-1BS region (63-93 Mb). This genomic region, harboring the Yr15 locus, has high LD levels (Figure S7). The highest association values were obtained by the multi-locus models Blink, FarmCPU, and MMLM for variant 1B:66240332, which was associated with the IT of PSTv-40 ( $p_{\text {adj }}=3.2 \times 10^{-82}, 3.9 \times 10^{-33}$, and $2.5 \times 10^{-16}$, respectively). The same variant was also highly associated with ITs to PST5006, according to FarmCPU $\left(p_{\text {adj }}=1.9 \times 10^{-9}\right)$. FarmCPU revealed a strong association of ITs to PSTv-37 with a nearby locus (1B:72049807, $p_{\text {adj }}=8.0 \times 10^{-14}$, Table 2).

Table 2. Association estimates of IT in the seedling stage for each Pst race. Variants were clustered into $40 \mathrm{Mb}$ windows using Zavitan WEW_v1.0 as a reference genome. ${ }^{1}$ Markers were aligned to QTL data from Wang and Chen (2017) [5].

\begin{tabular}{|c|c|c|c|c|c|c|c|}
\hline Chr & $\begin{array}{c}40 \mathrm{Mb} \\
\text { Window } \\
\text { Center } \mathrm{Mb}\end{array}$ & $\begin{array}{l}\text { No. of Race/Model } \\
\text { Combinations } \\
\text { Significant Results }\end{array}$ & Pst Race List & Models & $\begin{array}{c}\operatorname{Max} \\
-\log 10(p)\end{array}$ & $\underset{-\operatorname{Mog} 10\left(p_{\text {adj }}\right)}{\operatorname{Max}}$ & $\begin{array}{l}\text { Aligned } \\
\text { QTL }^{1}[5]\end{array}$ \\
\hline $1 \mathrm{~B}$ & 80 & 12 & $\begin{array}{c}37,40,5006 \\
14\end{array}$ & $\begin{array}{l}\text { Blink, CMLM, } \\
\text { FarmCPU, } \\
\text { MLMM }\end{array}$ & 86.83 & 81.52 & Yr15 [20] \\
\hline $1 \mathrm{~A}$ & 560 & 3 & 5006,37 & $\begin{array}{l}\text { Blink, CMLM, } \\
\text { FarmCPU }\end{array}$ & 30.83 & 25.52 & Q.1A.9 [62] \\
\hline $4 \mathrm{~B}$ & 640 & 4 & 5006 & $\begin{array}{l}\text { Blink, CMLM, } \\
\text { FarmCPU }\end{array}$ & 21.73 & 16.72 & Q.4B.14 [63] \\
\hline $3 \mathrm{~A}$ & 680 & 3 & 5006 & $\begin{array}{l}\text { Blink, CMLM, } \\
\text { FarmCPU }\end{array}$ & 15.25 & 9.94 & \\
\hline $2 \mathrm{~A}$ & 120 & 6 & 37 & $\begin{array}{l}\text { Blink, CMLM, } \\
\text { ECMLM, } \\
\text { FarmCPU, } \\
\text { MLMM, MLM }\end{array}$ & 9.25 & 4.15 & Q.2A.17 [64] \\
\hline $3 \mathrm{~A}$ & 720 & 5 & 5006,37 & $\begin{array}{l}\text { Blink, CMLM, } \\
\text { ECMLM, } \\
\text { MLMM, MLM }\end{array}$ & 8.44 & 3.43 & \\
\hline $4 \mathrm{~A}$ & 160 & 3 & 14 & $\begin{array}{c}\text { ECMLM, } \\
\text { MLMM, MLM }\end{array}$ & 7.72 & 2.42 & \\
\hline $2 B$ & 160 & 4 & 37 & $\begin{array}{l}\text { CMLM, } \\
\text { ECMLM, } \\
\text { FarmCPU, } \\
\text { MLM }\end{array}$ & 6.68 & 2.26 & $Y r 31$ [65] \\
\hline $1 \mathrm{~A}$ & 320 & 4 & 37 & $\begin{array}{l}\text { Blink, CMLM, } \\
\text { ECMLM, MLM }\end{array}$ & 6.54 & 1.84 & \\
\hline $5 B$ & 120 & 9 & 37 & $\begin{array}{c}\text { CMLM, } \\
\text { ECMLM, MLM }\end{array}$ & 6.08 & 1.62 & \\
\hline $1 \mathrm{~B}$ & 560 & 3 & 37,5006 & $\begin{array}{c}\text { Blink, } \\
\text { FarmCPU }\end{array}$ & 5.79 & 1.47 & Yrv3 [66] \\
\hline
\end{tabular}

\subsection{GWAS for APR}

The GWAS for APR-associated loci was performed using 11 methods from the GAPIT and mrMLM packages $[34,35]$. The GLM method from the GAPIT package was not included 
because of an inflated low $p$-value distribution. The pLARmEB method from the mrMLM package was not used due to technical problems.

Twenty significant variants were detected by at least two methods $\left(-\log _{10} p\right.$-value $\left.>4\right)$. The only marker that was detected using all methods was the PCR marker for Yr36 (Table 3). No significant variants from the GBS matrix were found near the Yr36 locus, probably because the gene region is deleted in the Zavitan reference genome [9,17]. To further test the significance of the markers, we included all of them as fixed variables in a mixed model using the IT scores from each of the 11 environments. The kinship matrix, environment (field), and genotype ID were used as random variables. The mixed model detected 13 significant markers, including the Yr36 marker $(p<0.005)$. All 13 markers remained highly significant $(p<0.001)$ after further testing of the model by 1000 permutations.

Table 3. Variants that are significantly associated with adult plant resistance. The results of GWAS with various models and results of mixed models, with all variants together, using the coxme::lmekin R function.

\begin{tabular}{|c|c|c|c|c|c|c|}
\hline Variants & $\begin{array}{l}\text { Minimum } \\
p \text {-Value of } \\
\text { GWAS }\end{array}$ & GWAS Models & $\begin{array}{l}\text { Estimate } \\
\text { lmekin }\end{array}$ & $\begin{array}{l}p \text {-Value } \\
\text { lmekin }\end{array}$ & $\underset{[5,6]}{\text { Aligned } \text { QTL }^{1}}$ & Putative Genes $^{2}$ \\
\hline 1A_571777232 & $9.20 \times 10^{-9}$ & $\begin{array}{l}\text { mrMLM, } \\
\text { FASTmrMLM, } \\
\text { pKWmEB }\end{array}$ & -0.198 & $1.30 \times 10^{-4}$ & $\begin{array}{c}\text { Q.1A. } 915 \%{ }^{3} \mathrm{~F}^{4} \\
{[62]}\end{array}$ & $\begin{array}{l}\text { TRIDC1AG060480 } \\
\text { WRKY domain [67] }\end{array}$ \\
\hline 1B_39276972 & $2.15 \times 10^{-10}$ & $\begin{array}{c}\text { mrMLM, } \\
\text { FASTmrMLM }\end{array}$ & 0.390 & $1.10 \times 10^{-12}$ & $\begin{array}{c}\text { MQTL4-1B 15\% F } \\
\text { [6] }\end{array}$ & $\begin{array}{l}\text { TRIDC1BG006690 } \\
\text { Papain-like cysteine } \\
\text { peptidase [68] }\end{array}$ \\
\hline 3B_550434503 & $7.03 \times 10^{-15}$ & $\begin{array}{l}\text { FASTmrMLM, } \\
\text { FASTmrEMMA }\end{array}$ & -0.295 & $6.20 \times 10^{-5}$ & Q.3B.24 6\% F [69] & $\begin{array}{l}\text { TRIDC3BG050030 } \\
\text { Eukaryotic translation } \\
\text { initiation factor } 3 \\
\text { subunit eif-3 [70] }\end{array}$ \\
\hline 3B_707838360 & $9.82 \times 10^{-10}$ & $\begin{array}{l}\text { FarmCPU, MLM, } \\
\text { BLINK, mrMLM, } \\
\text { FASTmrMLM }\end{array}$ & -0.221 & $1.80 \times 10^{-3}$ & & $\begin{array}{c}\text { TRIDC3BG067020 } \\
\text { Peptidase A22B, signal } \\
\text { peptide peptidase [71] }\end{array}$ \\
\hline 3B_88645297 & $5.40 \times 10^{-5}$ & $\begin{array}{l}\text { ECMLM, MLMM, } \\
\text { SUPER }\end{array}$ & -0.190 & $2.70 \times 10^{-3}$ & $\begin{array}{l}\text { Q.3B.8 6\% F [72] } \\
\text { Q.B3.9 20\% F [73] } \\
\text { Q.3B.10 5\% F [74] } \\
\text { Q3B.12 30\% F [75] } \\
\text { Q3B.14 5\% F [65] }\end{array}$ & $\begin{array}{l}\text { TRIDC3BG015830 } \\
\text { alpha/beta hydrolase } \\
\text { fold [76] }\end{array}$ \\
\hline 5B_157144166 & $8.75 \times 10^{-8}$ & $\begin{array}{l}\text { mrMLM, } \\
\text { FASTmrMLM, } \\
\text { pKWmEB }\end{array}$ & 0.371 & $2.30 \times 10^{-7}$ & Q.5B.2 6\% F [77] & $\begin{array}{c}\text { TRIDC5BG018210 } \\
\text { AIG1-type guanine } \\
\text { nucleotide-binding [78] }\end{array}$ \\
\hline 5B_24593659 & $3.12 \times 10^{-10}$ & $\begin{array}{l}\text { mrMLM, } \\
\text { FASTmrMLM }\end{array}$ & -0.337 & $1.30 \times 10^{-8}$ & $\begin{array}{l}\text { Q5B.2 6\% F [77] } \\
\text { Q5B.3 27\% [79] }\end{array}$ & $\begin{array}{l}\text { TRIDC5BG004210 } \\
\text { Methyl-CpG DNA } \\
\text { binding [80] }\end{array}$ \\
\hline 5B_527982577 & $2.32 \times 10^{-12}$ & $\begin{array}{c}\text { mrMLM, } \\
\text { FASTmrMLM }\end{array}$ & 0.205 & $2.30 \times 10^{-4}$ & $\begin{array}{c}\text { Q.5B.18 33\% [81] } \\
\text { Q5B.193\% F [82] } \\
\text { Q5B.20 30\% F [83] }\end{array}$ & $\begin{array}{l}\text { TRIDC5BG053620 } \\
\text { NAC domain [84] }\end{array}$ \\
\hline 6B_132922231 & $1.60 \times 10^{-7}$ & $\begin{array}{l}\text { FASTmrEMMA, } \\
\text { pKWmEB }\end{array}$ & -0.221 & $3.30 \times 10^{-3}$ & $\begin{array}{l}\text { Q.6B.3 15\% F [62] } \\
\text { Q.6B.6 35\% F [85] } \\
\text { Q.6B.7 6\% F [86] }\end{array}$ & $\begin{array}{c}\text { TRIDC6BG018950 } \\
\text { NB-ARC [87] }\end{array}$ \\
\hline 6B_138700000_Yr36 & $3.25 \times 10^{-23}$ & $\begin{array}{l}\text { CMLM, ECMLM, } \\
\text { FarmCPU, MLM, } \\
\text { MLMM, SUPER, } \\
\text { BLINK, mrMLM, } \\
\text { FASTmrMLM, } \\
\text { pKWmEB, ISIS } \\
\text { EM-BLASSO }\end{array}$ & -0.792 & $7.70 \times 10^{-12}$ & Yr36 F [9] & kinase_START \\
\hline
\end{tabular}


Table 3. Cont.

\begin{tabular}{|c|c|c|c|c|c|c|}
\hline Variants & $\begin{array}{l}\text { Minimum } \\
p \text {-Value of } \\
\text { GWAS }\end{array}$ & GWAS Models & $\begin{array}{l}\text { Estimate } \\
\text { lmekin }\end{array}$ & $\begin{array}{l}p \text {-Value } \\
\text { lmekin }\end{array}$ & $\underset{[5,6]}{\text { Aligned } \text { QTL }^{1}}$ & Putative Genes ${ }^{2}$ \\
\hline 6B_664322346 & $4.74 \times 10^{-5}$ & $\begin{array}{l}\text { ECMLM, MLMM, } \\
\text { SUPER }\end{array}$ & -0.206 & $3.90 \times 10^{-4}$ & $\begin{array}{l}\text { Q.6B.16 } \\
\text { Q.6B.17 } \\
\text { Q.6B.18 [5] }\end{array}$ & $\begin{array}{l}\text { TRIDC6BG064680 } \\
\text { WD repeat HIR1 [88] }\end{array}$ \\
\hline 7A_501622609 & $5.75 \times 10^{-13}$ & $\begin{array}{l}\text { FASTmrMLM, } \\
\text { pKWmEB }\end{array}$ & 0.260 & $5.00 \times 10^{-6}$ & Q.7A.9 6\% F [89] & $\begin{array}{l}\text { TRIDC7AG048010 } \\
\text { Ubiquitin-Conjugating } \\
\text { Enzyme E2 [90] }\end{array}$ \\
\hline 7B_105138786 & $6.93 \times 10^{-11}$ & $\begin{array}{l}\text { mrMLM, } \\
\text { FASTmrEMMA }\end{array}$ & -0.390 & $5.60 \times 10^{-9}$ & & $\begin{array}{c}\text { TRIDC7BG013060 } \\
\text { Cellulose Synthase } \\
\text { Interactive [91] }\end{array}$ \\
\hline
\end{tabular}

To ensure that the model was not overfitted, we used an Akaike information criterion (AIC) wherein all possible subset combinations of the 13 loci were tested. The full model had the lowest AIC, meaning it was the best model to describe the association of the 13 loci with ITs. We used a similar mixed model to test the variance explained by the different components. In this model, we tested the BLUP-ITs instead of the ITs of each field, to exclude field variations from the model. The pseudo- $R$-squared calculation, using the likelihood-ratio test, showed that the 13 genetic loci explained $83 \%$ of the variance, of which one-quarter was explained by $Y r 36$ and the rest by the other 12 loci. A similar mixed model was also used to test for interactions between $Y r 36$ and the other 12 variants; however, no significant interactions were detected $(p>0.05)$. The number of favorable alleles (i.e., alleles associated with IT reduction) in each genotype was calculated on the basis of the 12 variants and plotted against the BLUP-IT, once for genotypes with $Y r 36$ and once for genotypes without Yr36. The trend in both cases showed a clear negative correlation between the number of favorable alleles and the mean BLUP-IT, where genotypes with $Y r 36$ had lower BLUP-IT than those without $Y r 36$ (Figure 6). The interactions of the 12 variants and $Y r 36$ were visualized using boxplots (Figure S8). In 10 of the variants, the effect of the favorable allele was larger in the presence of $Y r 36$. Looking at the results from a different perspective, it was evident that all of the variants enhanced the positive effect of $Y r 36$ on resistance. The distribution of the 13 loci along the genome was uneven, with most (11) being detected in the $\mathrm{B}$-genome chromosomes ( $1 \mathrm{~B}$ and $7 \mathrm{~B}$, each with one; $3 \mathrm{~B}, 5 \mathrm{~B}$, and $6 \mathrm{~B}$, each with three) and two in chromosomes from the $\mathrm{A}$ genome (1A and $7 \mathrm{~A}$, each with one). 


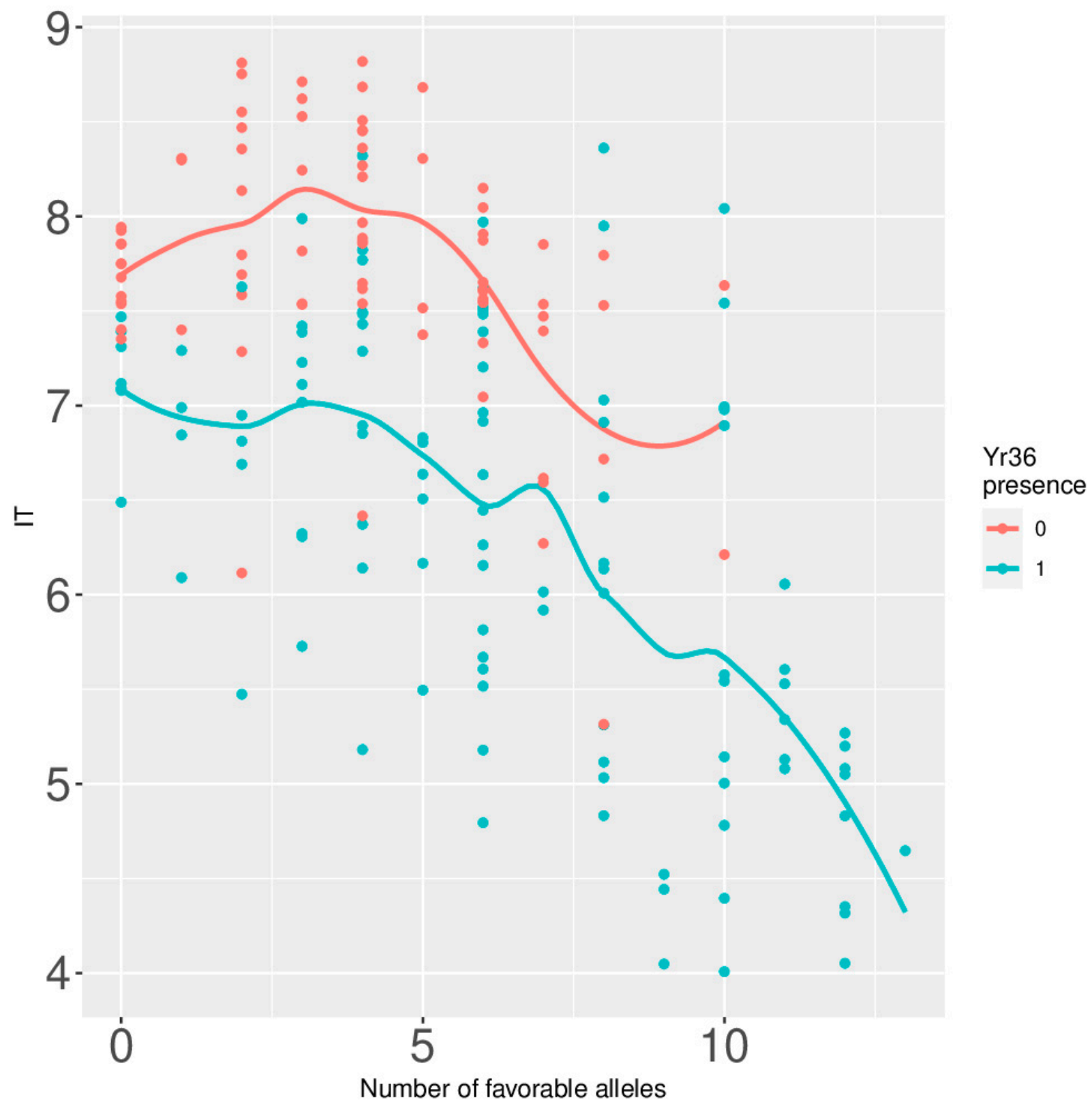

Figure 6. Correlation of infection types with the number of favorable alleles in wild emmer accessions. Colors indicate the presence (1, blue line and dots) and the absence ( 0 , red line and dots) of Yr36 in the genotype. $Y$-axis: BLUP values for infection types (BLUP-IT); X-axis: number of favorable (reducing IT) alleles of the 12 significant loci in each accession.

\section{Discussion}

The main goals of this study were to identify the loci associated with stripe rust resistance at the seedling stage (ASR) and the adult plant stage (APR), and to identify accessions that may carry novel APR or ASR resistance genes.

\subsection{LD Levels}

Linkage disequilibrium (LD) levels in the wild emmer population decayed very rapidly, within the first $1 \mathrm{~kb}$, as $r^{2}$ values were halved from $\sim 0.85$ to 0.425 . This rapid decay was observed in the same population, using the 9k SNP array [29], and in another WEW panel and a wild barley panel, using Sanger sequencing [92,93]. These LD estimates are much lower than the estimates in the selfing wild population of Arabidopsis thaliana, where LD decayed within $250 \mathrm{~kb}$ [94]. The estimates of LD extent in wild populations 
are several times lower than the LD extent in domesticated wheat, where LD can extend several centimorgans [38,95]. These low LD levels are favorable, in the sense that they increase the resolution of GWAS; however, a much higher marker density is required in the panel to detect significant associations [95].

\subsection{All-Stage Resistance}

The ASR GWAS identified two loci that were associated with UIT, indicating that they confer resistance to all four Pst races. Qpst.icci-1BS (63-93 Mb) colocalizes with the Yr15 locus [20]. This QTL extends over a wide interval, and LD analysis indicates that high LD levels in the region may be the reason (Figure S7). Therefore, it is highly probable that all of the associations found in this region are caused by $Y r 15$. However, the most significant associations from the GWAS did not identify the closest variant to the Yr15 locus. Testing for associations between Qpst.icci-1BS variants and the Yr15 KASP marker detected variants closer to the $Y r 15$ locus than the GWAS results, based on ITs. This means that the GBS-based GWAS in wild populations are limited in their precision, probably because of missing data, low allele frequencies, and variations in the phenotypic expression of resistance, due to the large diversity in the genetic background of accessions. This result may also suggest that other ASR genes are located in Qpst.icci-1BS but are masked by Yr15 and the LD block.

Qpst.icci-3AS ( 25 Mb) is located in the same region as $Y r 76$. This gene originated from the hexaploid club wheat cultivar, Tyee, which includes in its pedigree a stripe rust-resistant T. durum landrace from Ethiopia [96,97]. $Y r 76$ is genetically located $2.3 \mathrm{cM}$ proximal to wmc11, which is physically located at $\sim 168 \mathrm{Mb}$ of chromosome 3A in the Zavitan WEW_v1.0 reference genome (3AS:16784689) [98]. We cannot rule out the possibility that $Y r 76$ and Qpst.icci-3AS are at the same locus. Qpst.icci-3AS overlaps with Q3A.1, a QTL that was observed only once in one environment, probably originating from cv. Sarr (Figure S9) [5,99]. Qpst.icci-3AS is located between two copies of genes encoding a wall-associated receptor kinases (TRIDC3AG005570 and TRIDC3AG005580), which are located $60 \mathrm{~kb}$ apart. These genes may be involved in resistance to stripe rust [100,101].

Of the 10 race-specific loci, five loci were aligned with previously reported QTLs or genes, including Yr31 and Yrv3 (Table 2, Figure S9) [5].

Additional resistance genes may also be present in the WEW population from Israel. However, the masking effect of $Y r 15$, coupled with the low frequency of these putative genes, likely complicates their detection by GWAS. Nevertheless, we identified several accessions that do not have favorable alleles at these two QTLs, which may be useful for biparental linkage analysis.

The effect of the two QTLs, detected on the basis of UITs, was highly dependent on the Pst race used in the assay. For PST5006, the effect of the favorable allele of either locus on the IT was a shift from highly susceptible to highly resistant, while for PSTV-37, the shift was from moderately susceptible to moderately resistant. For PSTv-14 and PSTv-40, the IT shift was intermediate (Figure S5). This observation underlines the importance of using multiple pathogen races in plant resistance studies and reveals that the host-pathogen interactions are affected not only by virulence/avirulence patterns but also by varying aggressiveness in the pathogen.

\subsection{Adult Plant Resistance}

The GWAS for APR revealed that the main locus determining this trait in the WEW panel from Israel is $Y r 36$. However, the level of resistance is also affected by at least 12 additional minor-effect loci that have an additive effect. We observed that $Y$ r36 alone does not explain most of the variance in resistance to Pst of the WEW population.

Wang and Chen (2017) reported on 327 QTLs for stripe rust resistance in wheat, with many overlaps (Figure S9). More than 80 of these QTLs were identified using GWAS [5], and many were identified in field trials, suggesting that they may confer APR. Numerous additional QTLs for APR to Pst have been detected since 2017 [30-33,66]. We aligned 
the APR GWAS results with those QTLs reported in the QTL reviews of Wang and Chen (2017) and Jan et al. (2021) (Figure S9) [5,6]. We found that 3 of the 13 APR loci do not align with any previously identified QTL and, therefore, may be novel (Table 3). The remaining loci were aligned to previously published QTLs, with most being identified in field trials. However, many of these QTLs had large confidence intervals, were mapped against different genomes using a different panel or mapping population, or employed a different marker system. Therefore, it is difficult to determine with certainty whether the loci detected in the current study are allelic to previously published QTLs. However, we found several loci with a precise alignment to previously published narrow QTLs, potentially indicating that the loci from the current study are allelic to the previously published QTLs. These loci were 3B:88645297, which aligned with five QTLs, and with Yr4, which is not an APR gene [5], 5B:527982577, which aligned with three narrow APR QTLs, and the locus on 6B:664322346, which aligned with three APR QTLs [5] (Table 3, Figure S9). Nevertheless, none of the previously published QTLs originated directly from WEW. We searched for candidate genes in the vicinity of the SNPs (up to $1 \mathrm{Mbp}$ ) using WEWv1 annotation. We found genes that are involved in disease perception, such as NB-ARC and WD repeat HIR1; genes that are involved in regulation, such as WRKY and NAC; genes controlling cell-wall biosynthesis, such as cellulose synthase; genes controlling the ubiquitination of a pathogen effector (ubiquitin-conjugating enzyme); and genes controlling epigenetic regulation (methyl-CpG-binding domain) (Table 3).

\subsection{The Effect of Diverse Genetic Background on Major Gene Resistance}

The two main $Y r$ genes in the WEW Israeli gene pool are $Y r 15$ for ASR and $Y r 36$ for APR. Other resistance genes may be present, but their frequencies were too low to be detected by GWAS. However, we can detect resistant accessions that do not have the Yr15 or $Y$ r36 favorable alleles and cross them with a susceptible genotype to isolate the gene. The range of ITs observed in accessions that have $Y r 15$ or $Y r 36$ was wide. This indicates that the effects of these genes on Pst infection are impacted by the genotypic background. For Yr36, we showed that its effect is dependent on at least 12 other loci. We also know from our own observations that the effect of $Y r 15$ in its original source (accession G25) and in hexaploid wheat with Yr15 introgressions (such as Avocet-Yr15) is much stronger than what we have observed in the WEW panel in the field. These observations suggest that the discovery of novel resistance genes, especially those conferring APR, may be complicated by the highly heterogeneous background of accessions in wild populations.

\subsection{Performance of GWAS Methods}

We used two R packages for the GWAS of APR in WEW. Each package includes several GWAS methods. The mrMLM package has models for multiple variants, while GAPIT has models for single variants, as well as for multiple variants [34,35]. In the APR GWAS, 9 out of the 13 variants were detected only by multiple-variant methods from the mrMLM package, while only 2 variants were detected by GAPIT methods alone, and 2 variants were detected by both packages. It seems that the mrMLM package, which uses multivariant models, is better at detecting variants in the WEW quantitative APR GWAS. Our approach to detect MTAs consisted of three steps: (i) detecting the trait-associated variants by applying multiple GWAS models, either for multiple variants or single variants; (ii) validating and filtering the detected variants using a mixed model that tests all selected variants in one model and accounts for genotype relatedness and the variation between environments, with validation by permutation analysis; (iii) selecting the model with the best combination of variants based on the AIC criterion. This approach may help to overcome the reduction in the power of GWAS tests caused by the heterogeneity of genetic backgrounds in wild populations. Moreover, adding the environment (field) variance into the mixed model enhances the robustness of the model, leading to more reliable results. To the best of our knowledge, this is the first time that this combination of steps has been used for GWAS validation. We believe that this combination of analytical steps will enhance the 
power of GWAS and reduce false associations. For the ASR GWAS, we used only those models that were implemented in the GAPIT package since we were expecting single-gene resistance. In our study, the best-performing models were MMLM, FarmCPU, and Blink, which are multiple-variant models. The single-variant models (e.g., MLM, CMLM, and ECMLM) resulted in high $p$-values with more noise, while the SUPER and GLM models generated inflated low $p$-values (Figure S6).

\section{Conclusions}

We demonstrated that multiple-variant GWAS methods are able to detect major and minor resistance genes in wild wheat populations, using the GBS approach. However, we see value in increasing the marker density in genetically diverse populations of wild relatives, beyond the density provided by GBS technology, to increase the rate of markertrait association discovery. As demonstrated, reference- and GBS-based GWAS may miss key resistance genes due to the absence of the gene in the reference genome and due to very low LD levels. The advances in sequencing technologies and the drop in sequencing costs may facilitate high-resolution reference-free GWAS that can overcome these limitations.

Supplementary Materials: The following supporting information can be downloaded at https: / / www.mdpi.com/article/10.3390/crops2010005/s1: Table S1. Infection type data and passport data of the association panel; Table S2. ITs of the accessions; Table S3. Summary statistics of ITs from the fields; Figure S1. Geographical distribution of wild emmer genotypes in Israel and its vicinity. Colors represent the assignment of the genotype to a bin along the first principal component, as calculated by sPCA. Pie represents the proportion of genotypes assigned to the bins within $20 \times 20 \mathrm{~km}$. The size of the pie is proportional to the number of genotypes; Figure S2. PCA based on the GBS matrix of the wild emmer population. Colors represent BLUP-IT to Pst at the adult plant stage; Figure S3. Linkage disequilibrium (LD) levels along the wild emmer genome. Left, distance 0-10 kbp; Right, distance $0-1 \mathrm{Mbp}$; each dot is the mean of a $100 \mathrm{bp}$ window. Blue line, Loess averaging; Figure S4. Circular Manhattan plot of the associations with UIT at the seedling stage, using seven GWAS models. Red stars indicate significant associations after Bonferroni correction $(\alpha=0.01 / \mathrm{N})$; Figure S5. Seedling ITs in four $P$ st races partitioned into alleles in the two significant seedling resistance MTAs. The length of the line is proportional to the number of accessions with the same IT; Figure S6. QQ plots of GWAS results using the SUPER model with the seedling IT; Figure S7. Linkage disequilibrium $r^{2}$ estimates near the Yr15 locus on 1BS; Figure S8. Level of BLUP-IT at the adult plant stage. For each of the 12 significant loci, ITs are partitioned into four boxplots by the $Y r 36 \mathrm{X}$ allele combination; Figure S9. Chromosomal locations of wheat genes or quantitative trait loci (QTLs) for resistance to stripe rust. Resistance genes with permanent and provisional $Y r$ symbols are shown on the left, and QTLs are shown on the right of each chromosome. QTLs are coded by numbers and can be found in Table 5.4 of Wang and Chen (2017) [5]. Loci detected in the current study are indicated by colored boxes: red-APR; green-ASR UIT (unified IT); blue-ASR race-specific loci. The figure is based on Figure 5.1 in from Wang and Chen (2017) [5].

Author Contributions: M.T. conducted the field experiments in Israel and was assisted by J.R. for data collection. E.A. (Elina Adhikari) and K.W.J. conducted the GBS analysis. N.C., I.A.d.B. and X.C. conducted the field experiments in the USA. O.M., J.M. and P.B.Y. conducted the seedling experiments. X.C. donated the North American Pst races. S.E. extracted the DNA. S.E. and L.G. conducted molecular marker analysis. B.S., E.A. (Eduard Akhunov) and H.S. conceptualized the study, wrote the grant proposal, and supervised the experiments. H.S. conducted the statistical analysis and wrote the paper. All authors have read and agreed to the published version of the manuscript.

Funding: This research was funded by the BARD IS-4744-14 project and in part by the LiebermanOkinow Endowment at the University of Minnesota and the Minnesota Agricultural Experiment Station Project No. MIN-22-085: Exploiting Wild Relatives for Cultivated Wheat and Barley Improvement. E. Adhikari was also supported by the Bill and Melinda Gates Foundation (INV-004430).

Data Availability Statement: The raw reads of the GBS analysis were deposited to the SRA archive (https:/ /www.ncbi.nlm.nih.gov/sra) under project PRJNA751112. Infection type data and passport data are available in Supplementary Table S1. 


\begin{abstract}
Acknowledgments: We thank Tamas Szinyei from the University of Minnesota and Oxana Maatuk and Sophie Klausner from Tel Aviv University for their excellent technical assistance. We thank Roi Ben David and Imri Kayts for the free use of the fields in Zafriyya and Barkai respectively.
\end{abstract}

Conflicts of Interest: The authors declare no conflict of interest.

\title{
References
}

1. Savary, S.; Willocquet, L.; Pethybridge, S.J.; Esker, P.; McRoberts, N.; Nelson, A. The global burden of pathogens and pests on major food crops. Nat. Ecol. Evol. 2019, 3, 430-439. [CrossRef] [PubMed]

2. Chen, X. Pathogens which threaten food security: Puccinia striiformis, the wheat stripe rust pathogen. Food Secur. 2020, $12,239-251$. [CrossRef]

3. Liu, T.; Wan, A.; Liu, D.; Chen, X. Changes of Races and Virulence Genes in Puccinia striiformis f. sp. tritici, the Wheat Stripe Rust Pathogen, in the United States from 1968 to 2009. Plant Dis. 2017, 101, 1522-1532. [CrossRef] [PubMed]

4. Catalogue of Wheat Gene Symbols. Available online: https://shigen.nig.ac.jp/wheat/komugi/genes/symbolListPageAction.do? page $=-1$ (accessed on 18 November 2021).

5. Wang, M.; Chen, X. Stripe Rust Resistance. In Stripe Rust; Springer: Berlin/Heidelberg, Germany, 2017 ; pp. 353-558.

6. Jan, I.; Saripalli, G.; Kumar, K.; Kumar, A.; Singh, R.; Batra, R.; Sharma, P.K.; Balyan, H.S.; Gupta, P.K. Meta-QTLs and candidate genes for stripe rust resistance in wheat. Sci. Rep. 2021, 11, 22923. [CrossRef] [PubMed]

7. Krattinger, S.G.; Lagudah, E.S.; Spielmeyer, W.; Singh, R.P.; Huerta-Espino, J.; McFadden, H.; Bossolini, E.; Selter, L.L.; Keller, B. A Putative ABC Transporter Confers Durable Resistance to Multiple Fungal Pathogens in Wheat. Science 2009, 323, $1360-1363$. [CrossRef]

8. Milne, R.J.; Dibley, K.E.; Schnippenkoetter, W.; Mascher, M.; Lui, A.C.; Wang, L.; Lo, C.; Ashton, A.R.; Ryan, P.R.; Lagudah, E.S. The Wheat Lr67 Gene from the Sugar Transport Protein 13 Family Confers Multipathogen Resistance in Barley. Plant Physiol. 2018, 179, 1285-1297. [CrossRef]

9. Fu, D.; Uauy, C.; Distelfeld, A.; Blechl, A.; Epstein, L.; Chen, X.; Sela, H.; Fahima, T.; Dubcovsky, J. A Kinase-START Gene Confers Temperature-Dependent Resistance to Wheat Stripe Rust. Science 2009, 323, 1357-1360. [CrossRef]

10. He, F.; Pasam, R.; Shi, F.; Kant, S.; Keeble-Gagnere, G.; Kay, P.; Forrest, K.; Fritz, A.; Hucl, P.; Wiebe, K.; et al. Exome Sequencing Highlights the Role of Wild-Relative Introgression in Shaping the Adaptive Landscape of the Wheat Genome. Nat. Genet. 2019, 51, 896-904. [CrossRef]

11. Luo, M.-C.; Yang, Z.-L.; You, F.M.; Kawahara, T.; Waines, J.G.; Dvorak, J. The structure of wild and domesticated emmer wheat populations, gene flow between them, and the site of emmer domestication. Theor. Appl. Genet. 2007, 114, 947-959. [CrossRef]

12. Nave, M.; Avni, R.; Çakır, E.; Portnoy, V.; Sela, H.; Pourkheirandish, M.; Ozkan, H.; Hale, I.; Komatsuda, T.; Dvorak, J.; et al. Wheat domestication in light of haplotype analyses of the Brittle rachis 1 genes (BTR1-A and BTR1-B). Plant Sci. 2019, 285, 193-199. [CrossRef]

13. Özkan, H.; Willcox, G.; Graner, A.; Salamini, F.; Kilian, B. Geographic distribution and domestication of wild emmer wheat (Triticum dicoccoides). Genet. Resour. Crop Evol. 2010, 58, 11-53. [CrossRef]

14. Feldman, M.; Kislev, M.E. Domestication of emmer wheat and evolution of free-threshing tetraploid wheat. Isr. J. Plant Sci. 2007, 55, 207-221. [CrossRef]

15. Nevo, E.; Korol, A.B.; Beiles, A.; Fahima, T. Evolution of Wild Emmer and Wheat Improvement: Population Genetics, Genetic Resources, and Genome Organization of Wheat's Progenitor, Triticum dicoccoides; Springer Science \& Business Media: Berlin/Heidelberg, Germany, 2002; ISBN 978-3-540-41750-7.

16. Aaronsohn, A. Agricultural and Botanical Explorations in Palestine; US Government Printing Office: Washington, DC, USA, 1910.

17. Avni, R.; Nave, M.; Barad, O.; Baruch, K.; Twardziok, S.O.; Gundlach, H.; Hale, I.; Mascher, M.; Spannagl, M.; Wiebe, K.; et al. Wild emmer genome architecture and diversity elucidate wheat evolution and domestication. Science 2017, 357, 93-97. [CrossRef] [PubMed]

18. The International Wheat Genome Sequencing Consortium (IWGSC); Appels, R.; Eversole, K.; Stein, N.; Feuillet, C.; Keller, B.; Rogers, J.; Pozniak, C.J.; Choulet, F.; Distelfeld, A.; et al. Shifting the limits in wheat research and breeding using a fully annotated reference genome. Science 2018, 361, 7191. [CrossRef]

19. Maccaferri, M.; Harris, N.S.; Twardziok, S.O.; Pasam, R.K.; Gundlach, H.; Spannagl, M.; Ormanbekova, D.; Lux, T.; Prade, V.M.; Milner, S.G.; et al. Durum wheat genome highlights past domestication signatures and future improvement targets. Nat. Genet. 2019, 51, 885-895. [CrossRef]

20. Klymiuk, V.; Yaniv, E.; Huang, L.; Raats, D.; Fatiukha, A.; Chen, S.; Feng, L.; Frenkel, Z.; Krugman, T.; Lidzbarsky, G.; et al. Cloning of the wheat $Y r 15$ resistance gene sheds light on the plant tandem kinase-pseudokinase family. Nat. Commun. 2018, 9, 3735. [CrossRef]

21. Marais, G.F.; Pretorius, Z.A.; Wellings, C.R.; McCallum, B.; Marais, A.S. Leaf rust and stripe rust resistance genes transferred to common wheat from Triticum dicoccoides. Euphytica 2005, 143, 115-123. [CrossRef]

22. Zhang, H.; Zhang, L.; Wang, C.; Wang, Y.; Zhou, X.; Lv, S.; Liu, X.; Kang, Z.; Ji, W. Molecular mapping and marker development for the Triticum dicoccoides-derived stripe rust resistance gene YrSM139-1B in bread wheat cv. Shaanmai 139. Theor. Appl. Genet. 2015, 129, 369-376. [CrossRef] 
23. Elkot, A.F.; Singh, R.; Kaur, S.; Kaur, J.; Chhuneja, P. Mapping novel sources of leaf rust and stripe rust resistance introgressed from Triticum dicoccoides in cultivated tetraploid wheat background. J. Plant Biochem. Biotechnol. 2020, 30, 336-342. [CrossRef]

24. Klymiuk, V.; Fatiukha, A.; Fahima, T. Wheat tandem kinases provide insights on disease-resistance gene flow and host-parasite co-evolution. Plant J. 2019, 98, 667-679. [CrossRef]

25. Gou, J.-Y.; Li, K.; Wu, K.; Wang, X.; Lin, H.; Cantu, D.; Uauy, C.; Dobon-Alonso, A.; Midorikawa, T.; Inoue, K.; et al. Wheat Stripe Rust Resistance Protein WKS1 Reduces the Ability of the Thylakoid-Associated Ascorbate Peroxidase to Detoxify Reactive Oxygen Species. Plant Cell 2015, 27, 1755-1770. [CrossRef] [PubMed]

26. Huang, L.; Sela, H.; Feng, L.; Chen, Q.; Krugman, T.; Yan, J.; Dubcovsky, J.; Fahima, T. Distribution and haplotype diversity of WKS resistance genes in wild emmer wheat natural populations. Theor. Appl. Genet. 2016, 129, 921-934. [CrossRef] [PubMed]

27. Santure, A.W.; Garant, D. Wild GWAS-association mapping in natural populations. Mol. Ecol. Resour. 2018, 18, 729-738. [CrossRef] [PubMed]

28. Sela, H.; Ezrati, S.; Ben-Yehuda, P.; Manisterski, J.; Akhunov, E.; Dvorak, J.; Breiman, A.; Korol, A. Linkage disequilibrium and association analysis of stripe rust resistance in wild emmer wheat (Triticum turgidum ssp. dicoccoides) population in Israel. Theor. Appl. Genet. 2014, 127, 2453-2463. [CrossRef]

29. Long, L.; Yao, F.; Yu, C.; Ye, X.; Cheng, Y.; Wang, Y.; Wu, Y.; Li, J.; Wang, J.; Jiang, Q.; et al. Genome-Wide Association Study for Adult-Plant Resistance to Stripe Rust in Chinese Wheat Landraces (Triticum aestivum L.) From the Yellow and Huai River Valleys. Front. Plant Sci. 2019, 10, 596. [CrossRef]

30. Yang, F.; Liu, J.; Guo, Y.; He, Z.; Rasheed, A.; Wu, L.; Cao, S.; Nan, H.; Xia, X. Genome-Wide Association Mapping of Adult-Plant Resistance to Stripe Rust in Common Wheat (Triticum aestivum). Plant Dis. 2020, 104, 2174-2180. [CrossRef]

31. Juliana, P.; Singh, R.P.; Singh, P.; Poland, J.A.; Bergstrom, G.C.; Huerta-Espino, J.; Bhavani, S.; Crossa, J.; Sorrells, M.E. Genomewide association mapping for resistance to leaf rust, stripe rust and tan spot in wheat reveals potential candidate genes. Theor. Appl. Genet. 2018, 131, 1405-1422. [CrossRef]

32. Godoy, J.G.; Rynearson, S.; Chen, X.; Pumphrey, M. Genome-Wide Association Mapping of Loci for Resistance to Stripe Rust in North American Elite Spring Wheat Germplasm. Phytopathology 2018, 108, 234-245. [CrossRef]

33. Cheng, B.; Gao, X.; Cao, N.; Ding, Y.; Gao, Y.; Chen, T.; Xin, Z.; Zhang, L. Genome-wide association analysis of stripe rust-resistance loci in wheat accessions from southwestern China. J. Appl. Genet. 2020, 61, 37-50. [CrossRef]

34. Wang, J.; Zhang, Z. GAPIT Version 3: Boosting Power and Accuracy for Genomic Association and Prediction. bioRxiv 2020, 403170. [CrossRef]

35. Zhang, Y.-W.; Tamba, C.L.; Wen, Y.-J.; Li, P.; Ren, W.-L.; Ni, Y.-L.; Gao, J.; Zhang, Y.-M. mrMLM v4.0.2: An R Platform for Multi-locus Genome-wide Association Studies. Genom. Proteom. Bioinform. 2020, 18, 481-487. [CrossRef] [PubMed]

36. Baranwal, D.; Cu, S.; Stangoulis, J.; Trethowan, R.; Bariana, H.; Bansal, U. Identification of genomic regions conferring rust resistance and enhanced mineral accumulation in a HarvestPlus Association Mapping Panel of wheat. Theor. Appl. Genet. 2022, 1-18. [CrossRef] [PubMed]

37. Tomar, V.; Dhillon, G.S.; Singh, D.; Singh, R.P.; Poland, J.; Chaudhary, A.A.; Bhati, P.K.; Joshi, A.K.; Kumar, U. Evaluations of Genomic Prediction and Identification of New Loci for Resistance to Stripe Rust Disease in Wheat (Triticum aestivum L.). Front. Genet. 2021, 12, 710485. [CrossRef] [PubMed]

38. Liu, L.; Wang, M.; Zhang, Z.; See, D.R.; Chen, X. Identification of Stripe Rust Resistance Loci in U.S. Spring Wheat Cultivars and Breeding Lines Using Genome-Wide Association Mapping and Yr Gene Markers. Plant Dis. 2020, 104, 2181-2192. [CrossRef] [PubMed]

39. Habib, M.; Awan, F.S.; Sadia, B.; Zia, M.A. Genome-Wide Association Mapping for Stripe Rust Resistance in Pakistani Spring Wheat Genotypes. Plants 2020, 9, 1056. [CrossRef]

40. Gaurav, K.; Arora, S.; Silva, P.; Sánchez-Martín, J.; Horsnell, R.; Gao, L.; Brar, G.S.; Widrig, V.; Raupp, W.J.; Singh, N.; et al. Population genomic analysis of Aegilops tauschii identifies targets for bread wheat improvement. Nat. Biotechnol. 2021, 1-10. [CrossRef]

41. Line, R.F.; Qayoum, A. Virulence, Aggressiveness, Evolution, and Distribution of Races of Puccinia striiformis (the Cause of Stripe Rust of Wheat) in North America, 1968-87; USDA-ARS: Washington, DC, USA, 1992.

42. Wan, A.; Wang, X.; Kang, Z.; Chen, X. Variability of the Stripe Rust Pathogen. In Stripe Rust; Springer: Berlin/Heidelberg, Germany, 2017; pp. 35-154.

43. Large, E.C. Growth Stages in Cereals Illustration of the Feekes Scale. Plant Pathol. 1954, 3, 128-129. [CrossRef]

44. Huang, S.; Steffenson, B.; Sela, H.; Stinebaugh, K. Resistance of Aegilops longissima to the Rusts of Wheat. Plant Dis. 2018, 102, 1124-1135. [CrossRef]

45. Chen, X. Epidemiology and control of stripe rust [Puccinia striiformis f. sp. tritici] on wheat. Can. J. Plant Pathol. 2005, 27, 314-337. [CrossRef]

46. Cheng, J.; Yan, J.; Sela, H.; Manisterski, J.; Lewinsohn, D.; Nevo, E.; Fahima, T. Pathogen race determines the type of resistance response in the stripe rust-Triticum dicoccoides pathosystem. Physiol. Plant. 2010, 139, 269-279. [CrossRef]

47. Poland, J.A.; Brown, P.J.; Sorrells, M.E.; Jannink, J.-L. Development of High-Density Genetic Maps for Barley and Wheat Using a Novel Two-Enzyme Genotyping-by-Sequencing Approach. PLoS ONE 2012, 7, e32253. [CrossRef]

48. Saintenac, C.; Jiang, D.; Wang, S.; Akhunov, E. Sequence-Based Mapping of the Polyploid Wheat Genome. G3 Genes Genomes Genet. 2013, 3, 1105-1114. [CrossRef] [PubMed] 
49. Glaubitz, J.C.; Casstevens, T.M.; Lu, F.; Harriman, J.; Elshire, R.J.; Sun, Q.; Buckler, E.S. TASSEL-GBS: A High Capacity Genotyping by Sequencing Analysis Pipeline. PLoS ONE 2014, 9, e90346. [CrossRef] [PubMed]

50. Browning, B.L.; Zhou, Y.; Browning, S.R. A One-Penny Imputed Genome from Next-Generation Reference Panels. Am. J. Hum. Genet. 2018, 103, 338-348. [CrossRef]

51. Dowle, M.; Srinivasan, A.; Short, T.; Lianoglou, S. Data. Table: Extension of 'Data.Frame'. Available online: https://cran.r-project. org/web/packages/data.table/index.html (accessed on 25 February 2019).

52. Frutos, E.; Galindo, M.P.; Leiva, V. An interactive biplot implementation in R for modeling genotype-by-environment interaction. Stoch. Environ. Res. Risk Assess. 2014, 28, 1629-1641. [CrossRef]

53. Endelman, J.B. Ridge Regression and Other Kernels for Genomic Selection with R Package rrBLUP. Plant Genome 2011, 4, 250-255. [CrossRef]

54. Kruijer, W.; Boer, M.P.; Malosetti, M.; Flood, P.J.; Engel, B.; Kooke, R.; Keurentjes, J.J.; van Eeuwijk, F.A. Marker-based estimation of heritability in immortal populations. Genetics 2015, 199, 379-398. [CrossRef]

55. Stacklies, W.; Redestig, H.; Scholz, M.; Walther, D.; Selbig, J. pcaMethods a bioconductor package providing PCA methods for incomplete data. Bioinformatics 2007, 23, 1164-1167. [CrossRef]

56. Jombart, T. adegenet: A R package for the multivariate analysis of genetic markers. Bioinformatics 2008, 24, 1403-1405. [CrossRef]

57. Jombart, T.; Devillard, S.; Dufour, A.-B.; Pontier, D. Revealing cryptic spatial patterns in genetic variability by a new multivariate method. Heredity 2008, 101, 92-103. [CrossRef]

58. Therneau, T.M. Coxme: Mixed Effects Cox Models. Available online: https://cran.r-project.org/web/packages/coxme/index. html (accessed on 3 August 2020).

59. Bartoń, K. MuMIn: Multi-Model Inference. Available online: https://cran.r-project.org/web/packages/MuMIn/index.html (accessed on 4 May 2020).

60. Akaike, H. Information theory and an extension of the maximum likelihood principle. In Selected papers of Hirotugu Akaike; Springer: New York, NY, USA, 1998; pp. 199-213.

61. Benjamini, Y.; Hochberg, Y. Controlling the False Discovery Rate: A Practical and Powerful Approach to Multiple Testing. J. R. Stat. Soc. Ser. B Methodol. 1995, 57, 289-300. [CrossRef]

62. Basnet, B.R.; Ibrahim, A.M.H.; Chen, X.; Singh, R.P.; Mason, E.R.; Bowden, R.L.; Liu, S.; Hays, D.B.; Devkota, R.N.; Subramanian, N.K.; et al. Molecular Mapping of Stripe Rust Resistance in Hard Red Winter Wheat TAM 111 Adapted to the U.S. High Plains. Crop Sci. 2014, 54, 1361-1373. [CrossRef]

63. Suenaga, K.; Singh, R.P.; Huerta-Espino, J.; William, H.M. Microsatellite Markers for Genes Lr34/Yr18 and Other Quantitative Trait Loci for Leaf Rust and Stripe Rust Resistance in Bread Wheat. Phytopathology 2003, 93, 881-890. [CrossRef] [PubMed]

64. Bulli, P.; Zhang, J.; Chao, S.; Chen, X.; Pumphrey, M. Genetic Architecture of Resistance to Stripe Rust in a Global Winter Wheat Germplasm Collection. G3 Genes Genomes Genet. 2016, 6, 2237-2253. [CrossRef]

65. Singh, R.; William, H.; Huerta-Espino, J.; Crosby, M. Identification and Mapping of Gene Yr31 for Resistance to Stripe Rust in Triticum Aestivum Cultivar Pastor. In Proceedings of the 10th International Wheat Genetics Symposium, Paestum, Italy, 1-6 September 2003; Pogna, N.E., Romana, M., Pogna, E.A., Galterio, G., Eds.; Instituto Sperimentale per la Cerealicoltura: Rome, Italy, 2003; pp. 411-413.

66. Hou, L.; Ma, D.-F.; Hu, M.-L.; He, M.-M.; Lu, Y.; Jing, J.-X. Genetic Analysis and Molecular Mapping of an All-Stage Stripe Rust Resistance Gene in Triticum aestivum-Haynaldia villosa Translocation Line V3. J. Integr. Agric. 2013, 12, 2197-2208. [CrossRef]

67. Jimmy, J.L.; Babu, S. Role of OsWRKY transcription factors in rice disease resistance. Trop. Plant Pathol. 2015, 40, 355-361. [CrossRef]

68. Shindo, T.; Van Der Hoorn, R.A.L. Papain-like cysteine proteases: Key players at molecular battlefields employed by both plants and their invaders. Mol. Plant Pathol. 2007, 9, 119-125. [CrossRef]

69. Christopher, M.D.; Liu, S.; Hall, M.D.; Marshall, D.S.; Fountain, M.O.; Johnson, J.W.; Milus, E.A.; Garland-Campbell, K.A.; Chen, X.; Griffey, C.A. Identification and Mapping of Adult Plant Stripe Rust Resistance in Soft Red Winter Wheat VA00W-38. Crop Sci. 2013, 53, 871-879. [CrossRef]

70. Erayman, M.; Turktas, M.; Akdogan, G.; Gurkok, T.; Inal, B.; Ishakoglu, E.; Ilhan, E.; Unver, T. Transcriptome analysis of wheat inoculated with Fusarium graminearum. Front. Plant Sci. 2015, 6, 867. [CrossRef]

71. Figueiredo, L.; Santos, R.; Figueiredo, A. Defense and Offense Strategies: The Role of Aspartic Proteases in Plant-Pathogen Interactions. Biology 2021, 10, 75. [CrossRef]

72. Basnet, B.R.; Singh, R.P.; Ibrahim, A.M.H.; Herrera-Foessel, S.A.; Huerta-Espino, J.; Lan, C.; Rudd, J.C. Characterization of Yr54 and other genes associated with adult plant resistance to yellow rust and leaf rust in common wheat Quaiu 3. Mol. Breed. 2013, 33, 385-399. [CrossRef]

73. Zhou, X.L.; Zhang, Y.; Zeng, Q.D.; Chen, X.M.; Han, D.J.; Huang, L.L.; Kang, Z.S. Identification of QTL for adult plant resistance to stripe rust in Chinese wheat landrace Caoxuan 5. Euphytica 2015, 204, 627-634. [CrossRef]

74. Lan, C.; Rosewarne, G.M.; Singh, R.P.; Herrera-Foessel, S.A.; Huerta-Espino, J.; Basnet, B.R.; Zhang, Y.; Yang, E. QTL characterization of resistance to leaf rust and stripe rust in the spring wheat line Francolin\#1. Mol. Breed. 2014, 34, 789-803. [CrossRef]

75. Case, A.J.; Naruoka, Y.; Chen, X.; Garland-Campbell, K.; Zemetra, R.S.; Carter, A.H. Mapping Stripe Rust Resistance in a BrundageXCoda Winter Wheat Recombinant Inbred Line Population. PLoS ONE 2014, 9, e91758. [CrossRef] 
76. Kumar, D. Salicylic acid signaling in disease resistance. Plant Sci. 2014, 228, 127-134. [CrossRef] [PubMed]

77. Yang, E.; Li, G.; Li, L.; Zhang, Z.; Yang, W.; Peng, Y.; Zhu, Y.; Yang, Z.; Rosewarne, G.M. Characterization of Stripe Rust Resistance Genes in the Wheat Cultivar Chuanmai45. Int. J. Mol. Sci. 2016, 17, 601. [CrossRef]

78. Pelgrom, A.J.E.; Meisrimler, C.-N.; Elberse, J.; Koorman, T.; Boxem, M.; van den Ackerveken, G. Host Targets of Effectors of the Lettuce Downy Mildew Bremia Lactucae from CDNA-Based Yeast Two-Hybrid Screening. PLoS ONE 2020, 15, e0226540. [CrossRef]

79. Lu, Y.; Wang, M.; Chen, X.; See, D.; Chao, S.; Jing, J. Mapping of Yr62 and a small-effect QTL for high-temperature adult-plant resistance to stripe rust in spring wheat PI 192252. Theor. Appl. Genet. 2014, 127, 1449-1459. [CrossRef]

80. Chen, Y.; Li, Y.; Ren, H.; Zhou, J.; Wang, L.; Yang, Y.; Hao, X.; Wang, X. Genome-wide identification and expression profiling reveal the diverse role of Methyl-CpG-binding domain proteins in tea plant Camellia sinensis. Beverage Plant Res. 2021, 1, 10. [CrossRef]

81. Feng, J.; Zuo, L.L.; Zhang, Z.Y.; Lin, R.M.; Cao, Y.Y.; Xu, S.C. Quantitative trait loci for temperature-sensitive resistance to Puccinia striiformis f. sp. tritici in wheat cultivar Flinor. Euphytica 2010, 178, 321-329. [CrossRef]

82. Lu, Y.; Lan, C.; Liang, S.; Zhou, X.; Liu, D.; Zhou, G.; Lu, Q.; Jing, J.; Wang, M.; Xia, X.; et al. QTL mapping for adult-plant resistance to stripe rust in Italian common wheat cultivars Libellula and Strampelli. Theor. Appl. Genet. 2009, 119, 1349-1359. [CrossRef] [PubMed]

83. Mallard, S.; Gaudet, D.; Aldeia, A.; Abelard, C.; Besnard, A.L.; Sourdille, P.; Dedryver, F. Genetic analysis of durable resistance to yellow rust in bread wheat. Theor. Appl. Genet. 2005, 110, 1401-1409. [CrossRef] [PubMed]

84. Yuan, X.; Wang, H.; Cai, J.; Li, D.; Song, F. NAC transcription factors in plant immunity. Phytopathol. Res. 2019, 1, 3. [CrossRef]

85. Santra, D.K.; Chen, X.M.; Santra, M.; Campbell, K.G.; Kidwell, K.K. Identification and mapping QTL for high-temperature adult-plant resistance to stripe rust in winter wheat (Triticum aestivum L.) cultivar 'Stephens'. Theor. Appl. Genet. 2008, 117, 793-802. [CrossRef]

86. Bariana, H.S.; Bansal, U.; Schmidt, A.; Lehmensiek, A.; Kaur, J.; Miah, H.; Howes, N.; McIntyre, C. Molecular mapping of adult plant stripe rust resistance in wheat and identification of pyramided QTL genotypes. Euphytica 2010, 176, 251-260. [CrossRef]

87. Steele, J.F.C.; Hughes, R.K.; Banfield, M.J. Structural and biochemical studies of an NB-ARC domain from a plant NLR immune receptor. PLoS ONE 2019, 14, e0221226. [CrossRef] [PubMed]

88. Zhao, X.-Y.; Qi, C.-H.; Jiang, H.; Zheng, P.-F.; Zhong, M.-S.; Zhao, Q.; You, C.-X.; Li, Y.-Y.; Hao, Y.-J. Functional identification of apple on MdHIR4 in biotic stress. Plant Sci. 2019, 283, 396-406. [CrossRef] [PubMed]

89. Liu, J.; He, Z.; Wu, L.; Bai, B.; Wen, W.; Xie, C.; Xia, X. Genome-Wide Linkage Mapping of QTL for Adult-Plant Resistance to Stripe Rust in a Chinese Wheat Population Linmai x Zhong 892. PloS ONE 2015, 10, e0145462. [CrossRef]

90. Liu, X.; Song, L.; Zhang, H.; Lin, Y.; Shen, X.; Guo, J.; Su, M.; Shi, G.; Wang, Z.; Lu, G. Rice ubiquitin-conjugating enzyme OsUBC26 is essential for immunity to the blast fungus Magnaporthe oryzae. Mol. Plant Pathol. 2021, 22, 1613-1623. [CrossRef]

91. Douchkov, D.; Lueck, S.; Hensel, G.; Kumlehn, J.; Rajaraman, J.; Johrde, A.; Doblin, M.S.; Beahan, C.T.; Kopischke, M.; Fuchs, R.; et al. The barley (Hordeum vulgare) cellulose synthase-like D2 gene (HvCsID2) mediates penetration resistance to host-adapted and nonhost isolates of the powdery mildew fungus. New Phytol. 2016, 212, 421-433. [CrossRef]

92. Sela, H.; Loutre, C.; Keller, B.; Schulman, A.; Nevo, E.; Korol, A.; Fahima, T. Rapid linkage disequilibrium decay in the Lr10 gene in wild emmer wheat (Triticum dicoccoides) populations. Theor. Appl. Genet. 2010, 122, 175-187. [CrossRef] [PubMed]

93. Morrell, P.; Toleno, D.M.; Lundy, K.E.; Clegg, M.T. Low levels of linkage disequilibrium in wild barley (Hordeum vulgare ssp. spontaneum) despite high rates of self-fertilization. Proc. Natl. Acad. Sci. USA 2005, 102, 2442-2447. [CrossRef] [PubMed]

94. Nordborg, M.; Borevitz, J.; Bergelson, J.; Berry, C.C.; Chory, J.; Hagenblad, J.; Kreitman, M.; Maloof, J.; Noyes, T.; Oefner, P.J.; et al. The extent of linkage disequilibrium in Arabidopsis thaliana. Nat. Genet. 2002, 30, 190-193. [CrossRef]

95. Chao, S.; Dubcovsky, J.; Dvorak, J.; Luo, M.-C.; Baenziger, S.P.; Matnyazov, R.; Clark, D.R.; Talbert, L.E.; Anderson, J.A.; Dreisigacker, S.; et al. Population- and genome-specific patterns of linkage disequilibrium and SNP variation in spring and winter wheat (Triticum aestivum L.). BMC Genom. 2010, 11, 727. [CrossRef] [PubMed]

96. GRIN-Global. Available online: https://npgsweb.ars-grin.gov/gringlobal/search (accessed on 8 December 2021).

97. GRIS. Available online: http:/ / www.wheatpedigree.net/ (accessed on 8 December 2021).

98. Xiang, C.; Feng, J.Y.; Wang, M.N.; Chen, X.M.; See, D.R.; Wan, A.M.; Wang, T. Molecular Mapping of Stripe Rust Resistance Gene Yr76 in Winter Club Wheat Cultivar Tyee. Phytopathology 2016, 106, 1186-1193. [CrossRef] [PubMed]

99. Lillemo, M.; Asalf, B.; Singh, R.; Huerta-Espino, J.; Chen, X.; He, Z.; Bjørnstad, Å. The Adult Plant Rust Resistance Loci Lr34/Yr18 and Lr46/Yr29 Are Important Determinants of Partial Resistance to Powdery Mildew in Bread Wheat Line Saar. Theor. Appl. Genet. 2008, 116, 1155-1166. [CrossRef] [PubMed]

100. Dmochowska-Boguta, M.; Kloc, Y.; Zielezinski, A.; Werecki, P.; Nadolska-Orczyk, A.; Karlowski, W.M.; Orczyk, W. TaWAK6 encoding wall-associated kinase is involved in wheat resistance to leaf rust similar to adult plant resistance. PLoS ONE 2020, 15, e0227713. [CrossRef]

101. Ensembl Genomes Triticum_dicoccoides. Available online: http://plants.ensembl.org/Triticum_dicoccoides/Info/Index (accessed on 8 December 2021). 